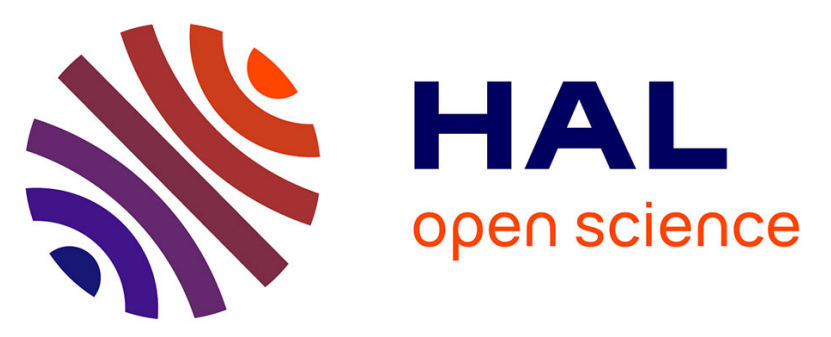

\title{
Early life stress in mice is a suitable model for Irritable Bowel Syndrome but does not predispose to colitis nor increase susceptibility to enteric infections
}

\author{
Ambre Riba, Maïwenn Olier, Sonia Lacroix-Lamandé, Corinne Lencina, \\ Valérie Alquier-Bacquié, Cherryl Harkat, N. van Langendonck, Christel \\ Cartier, Marine Baron, Caroline Sommer, et al.
}

\section{To cite this version:}

Ambre Riba, Maïwenn Olier, Sonia Lacroix-Lamandé, Corinne Lencina, Valérie Alquier-Bacquié, et al.. Early life stress in mice is a suitable model for Irritable Bowel Syndrome but does not predispose to colitis nor increase susceptibility to enteric infections. Brain, Behavior, and Immunity, 2018, 73, pp.403-4015. 10.1016/j.bbi.2018.05.024 . hal-02621451

\section{HAL Id: hal-02621451 \\ https://hal.inrae.fr/hal-02621451}

Submitted on 26 May 2020

HAL is a multi-disciplinary open access archive for the deposit and dissemination of scientific research documents, whether they are published or not. The documents may come from teaching and research institutions in France or abroad, or from public or private research centers.
L'archive ouverte pluridisciplinaire HAL, est destinée au dépôt et à la diffusion de documents scientifiques de niveau recherche, publiés ou non, émanant des établissements d'enseignement et de recherche français ou étrangers, des laboratoires publics ou privés. 


\section{Accepted Manuscript}

Early life stress in mice is a suitable model for Irritable Bowel Syndrome but does not predispose to colitis nor increase susceptibility to enteric infections

A. Riba, M Olier, S. Lacroix-Lamandé, C. Lencina, V. Bacquié, C. Harkat, N. Van Langendonck, M. Gillet, C. Cartier, M. Baron, C. Sommer, V. Mallet, M Zill, H. Robert, F. Laurent, S. Ellero-Simatos, V. Théodorou, S. Ménard

PII: S0889-1591(18)30200-9

DOI: https://doi.org/10.1016/j.bbi.2018.05.024

Reference: YBRBI 3413

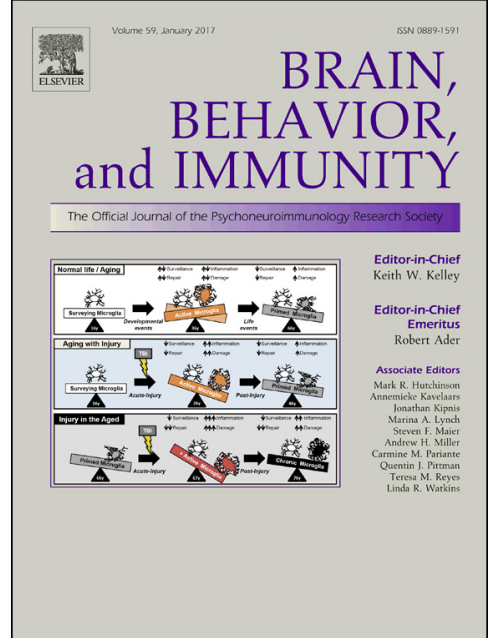

To appear in:

Brain, Behavior, and Immunity

Received Date: $\quad 9$ February 2018

Revised Date: $\quad 17$ May 2018

Accepted Date: $\quad 30$ May 2018

Please cite this article as: Riba, A., Olier, M., Lacroix-Lamandé, S., Lencina, C., Bacquié, V., Harkat, C., Van Langendonck, N., Gillet, M., Cartier, C., Baron, M., Sommer, C., Mallet, V., Zill, M., Robert, H., Laurent, F., ElleroSimatos, S., Théodorou, V., Ménard, S., Early life stress in mice is a suitable model for Irritable Bowel Syndrome but does not predispose to colitis nor increase susceptibility to enteric infections, Brain, Behavior, and Immunity (2018), doi: https://doi.org/10.1016/j.bbi.2018.05.024

This is a PDF file of an unedited manuscript that has been accepted for publication. As a service to our customers we are providing this early version of the manuscript. The manuscript will undergo copyediting, typesetting, and review of the resulting proof before it is published in its final form. Please note that during the production process errors may be discovered which could affect the content, and all legal disclaimers that apply to the journal pertain. 
Title:

Early life stress in mice is a suitable model for Irritable Bowel Syndrome but does not predispose to colitis nor increase susceptibility to enteric infections

A. Riba ${ }^{1}$, M Olier $^{1}$, S. Lacroix-Lamandé ${ }^{2}$, C. Lencina ${ }^{1}$, V. Bacquié ${ }^{1}$, C. Harkat ${ }^{1}$, N. Van Langendonck $^{3}$, M. Gillet ${ }^{1}$, C. Cartier ${ }^{1}$, M. Baron ${ }^{1}$, C. Sommer ${ }^{1}$, V. Mallet ${ }^{1}$, M Zill ${ }^{4}$, H. Robert $^{1,4}$, F. Laurent ${ }^{2}$, S. Ellero-Simatos ${ }^{5}$, V. Théodorou ${ }^{1}$, S. Ménard ${ }^{1}$

\section{Author affiliation:}

${ }^{1}$ INRA, ToxAlim (Research Centre in Food Toxicology), team Neuro-Gastroenterology and Nutrition, Toulouse, France

2 Equipe Apicomplexes et Immunité Mucosale (AIM), UMR 1282 INRA/UniversitéInfectiologie et Santé Publique (ISP), Centre INRA Val de Loire, Nouzilly, FRANCE

${ }^{3}$ Service de Parasitologie-Mycologie-Médecine Tropicale, CHRU, Tours, France.

${ }^{4}$ Institut Universitaire de Technologie, Université Paul Sabatier, Auch, France

${ }^{5}$ INRA, ToxAlim (Research Centre in Food Toxicology) team Integrative Toxicology and Metabolism, Toulouse, France

Corresponding author: Sandrine Ménard, Neuro-Gastroenterology \& Nutrition, INRA, 180 Chemin de Tournefeuille, BP93173, 31027 Toulouse cedex 3, France. Phone: +33 5612857 59; email:sandrine.menard@inra.fr

Running title: Long-term effects of maternal separation on gastrointestinal diseases susceptibility 
Abstract: Neonatal period is characterized by an immature intestinal barrier. Scattered evidence suggests that early life stressful events induce long lasting alterations of intestinal homeostasis mimicking Irritable Bowel Syndrome (IBS). Those observations highlighting defect of intestinal barrier by early life stress questioned its potential role as a risk factor for gastrointestinal disorders such as colitis and infections. In this study, we aimed to analyze if maternal separation (MS) in mice gathers IBS main features. We next addressed whether MS could trigger or exacerbate colitis in genetically predisposed mice and/or enhance susceptibility to gastrointestinal infections in wild type mice. MS induced main features of IBS in adult wild type male mice i.e. intestinal hyperpermeability, visceral hypersensitivity, microbiota dysbiosis, bile acid malabsorption and low grade inflammation in intestine associated with a defect of Paneth cells and the ILC3 population. This breach in mucosal barrier functions in adults was associated with a systemic IgG response against commensal $E$. coli and increased IFN $\gamma$ secretion by splenocytes. However, in IL10 ${ }^{-/-}$mice, MS did not trigger nor worsen colitis. Furthermore, wild type mice submitted to MS did not show increase susceptibility to gastrointestinal infections ( $S$. Typhimurium, L. monocytogenes or $T$. gondii) compared to controls. Altogether, our results identify MS in mice as a good experimental model for IBS mimicking all the main features. In addition, early life stress, even though it has long lasting consequences on intestinal homeostasis, does not constitute a facilitating factor to colitis in predisposed individuals nor to gastrointestinal infections in wild type mice.

Keywords: Maternal separation, humoral and cellular response toward microbiota, proinflammatory $\mathrm{T}$ cell response, innate and adaptive immune responses. 
Abbreviations: AMP, antimicrobial peptides; CD: Crohn's disease; GALT, Gut Associated

Lymphoid Tissue; IBD, Inflammatory Bowel Disease; IBS, Irritable Bowel Syndrome; Ig,

Immunoglobulin; ILC, Innate Lymphoid Cells; MS, Maternal Separation.

\section{Highlights:}

- Early life stress in mice is a unique model mimicking IBS features i.e. visceral hypersensitivity, intestinal hyper-permeability, lowgrade inflammation, microbiota dysbiosis and bile acid malabsorption.

- Early life stress does not precipitate nor exacerbate colitis in mouse models genetically predisposed to IBD

- Early life stress does not increase susceptibility to gastrointestinal pathogen infections.

- Early life stress induces long lasting consequences on intestinal barrier that do not impair the ability of intestinal barrier to prevent enteric infections or contain colitis. This result is consistent with epidemiological studies. 


\section{Introduction}

Irritable Bowel Syndrome (IBS) is a functional gastrointestinal disorder newly called "Disorder of the gut-brain interaction" according to Rome IV classification (Drossman, 2016). It is characterized by abdominal pain and altered bowel habits (Drossman, 2006). It is highly prevalent $(\sim 11 \%)$ in Europe and in the United States (Lovell and Ford, 2012). The occurrence of stressful events is considered as a contributing factor triggering and/or maintaining IBS (Mayer et al., 2001; Wood, 2011), suggesting that dysfunctional interactions in the brain-gut axis contribute to the pathophysiology of the disease (Bonaz and Bernstein, 2013) and as such justifying it's new classification as Disorder of the brain-gut interaction (Drossman, 2016). Beside visceral pain, IBS is also characterized by increased intestinal permeability (Bischoff et al., 2014), microbiota dysbiosis (for review (Collins, 2014)) and increased state of activation of immune cells (Barbara et al., 2011) even though this last observation is still under debate. Early life events draw particular attention since they were associated with IBS susceptibility (Hislop, 1979; Lowman et al., 1987; Videlock et al., 2009). The perinatal period is a crucial and critical window where the intestinal barrier, the immune system and the gut microbiota mature and establish an appropriate complex relationship (Renz et al., 2012). Maternal separation (MS) is an established model of early life stress in rodent (for review (Marco et al., 2015; O’Mahony et al., 2011)). Data from various studies show that maternal separation (MS) induces in rats many features of IBS i.e. visceral hypersensitivity (Barreau et al., 2004), intestinal hyperpermeability (Barreau et al., 2004) and microbiota dysbiosis (O’Mahony et al., 2009; Zhou, 2016). However, so far there is no study showing all IBS features in a single experimental model. Furthermore, as MS appears to weaken the intestinal barrier and exacerbates intestinal and systemic immune responses at adulthood, we questioned its role as a risk factor for susceptibility to inflammatory bowel diseases (IBD) or gastrointestinal infections. 
In this study, we analyzed the consequences of adverse stressful events occurrence in neonatal mice on the development of IBS symptoms, i.e. visceral hypersensitivity, intestinal hyperpermeability, microbiota dysbiosis and immune cells activation. Next, we hypothesized that if early stressful events impair intestinal barrier functions, it might be associated with a loss of immune tolerance toward luminal contents. Then, we assessed if the MS-induced alteration of intestinal barrier and exacerbation of immune response may trigger or exacerbate colitis in the IBD model of $\mathrm{IL} 10^{-/-}$mice or make wild type mice more susceptible to gastrointestinal infectious challenge with bacterial pathogens (Listeria monocytogenes, Salmonella typhimurium) or parasites (Toxoplasma gondii). More generally, the question of wherever early life adverse events are weakening the organism or not is of particular interest. It is admitted that neonate respond to an adverse environment by making developmental adaptations that are likely to increase survival and resilience in the anticipated deprived environment. Therefore perinatal adversity may affect immunity in such a way to allow the organism to better cope with a stressful environment (for review (Avitsur et al., 2015)). This statement is counterintuitive and needs scientific evidence.

\section{Material and Methods}

All experimental protocols described in this study were approved by the local Animal Care Use Committee (Comité d'Ethique de Pharmacologie-Toxicologie de Toulouse - MidiPyrénées, France) registered as $\mathrm{N}^{\circ} 86$ at the Ministry of Research and Higher Education $\left(\mathrm{N}^{\circ}\right.$ 0029/SMVT), and conducted in accordance with the European directive 2010/63/UE. All experiments were performed on mice aged of 50 days (D50). All animals were euthanized by cervical dislocation. 


\subsection{Animals}

In all experiments, mice were kept at a constant temperature $\left(22+/-1^{\circ} \mathrm{C}\right)$ and maintained on a 12:12h light/dark cycle (light on at 7h30 am). Food (Harlan, Gannat, France) and water were available ad libitum. After delivery (D1), litters were adjusted to $6 \pm 1$ pups. Weaning was performed on D21, siblings were sex matched and the animals were kept under Specific and Opportunistic Pathogen Free (SOPF) conditions.

\section{Maternal separation}

Nulliparous female C3H/HeN mice (Janvier, Roubaix, France) or C57BL/6 IL10 ${ }^{-/}$(kindly provided by Dr Manuela Büttner) were mated with males for 4 days. Maternal separation (MS) was performed daily for three consecutive hours (from 9 am to $12 \mathrm{pm}$ ). Pups were kept at a controlled temperature $\left(27+/-1^{\circ} \mathrm{C}\right)$. MS was repeated for 10 working days, weekend excluded, between D2 and D15 as already published (Barreau et al., 2004). Repeated maternal deprivation during Hypothalamic Pituitary Axis development (PND2 to PND15) have been shown to have long lasting consequences in offspring behaviors and physiology (for review (O’Mahony et al., 2011)). Control pups were left with their dam and were not manipulated. From D15 to D21, all pups were maintained with their dam. Only male mice were kept for the following experiments to avoid female hormonal cycle interference.

Weight was monitored every week between D2 and D50.

Infections with Salmonella enterica subsp. enterica serotype Typhimurium (S. Typhimurium), Listeria monocytogenes or Toxoplama gondii

We analyzed three models of intestinal pathogens: S. Typhimurium (bacterial pathogen), L. monocytogenes (intracellular bacterial pathogen) and T. gondii (intracellular pathogen 
parasite). PND50 $\mathrm{C} 3 \mathrm{H} / \mathrm{HeN}$ male mice were orally challenged by intra-gastric gavage with $10^{9} \mathrm{CFU}$ of Salmonella Typhimurium 14028s (pACYC177), or $10^{9} \mathrm{CFU}$ of Listeria monocytogenes Lmo-InIA ${ }^{\mathrm{m}}$ expressing the internalin recognized by the murine E-cadherin (Wollert et al., 2007) or 35 cysts of Toxoplasma gondii 76K. Mice were weighted and euthanatized seven or five days post infection respectively with $S$. Typimurium and $T$. gondii or L. monocytogenes. Then small intestine, ileum, liver and/or spleen were mashed through a $70 \mu \mathrm{m}$ nylon mesh and plated on McConkey supplemented with $50 \mu \mathrm{g} / \mathrm{ml}$ kanamycin for $S$. Typhimurium or ChromID Lmono for L. monocytogenes and incubated at $37^{\circ} \mathrm{C}$ for 24 and 48H respectively. For $T$. gondii, DNA extraction was performed with the kit Genomic DNA from Tissue (Macherey-Nagel, Germany). Real time PCR was performed on $1 \mu \mathrm{g}$ of total DNA in a total volume of $25 \mu$ containing Platinium ${ }^{\circledR}$ Quantitative PCR Super Mix-UDG (Uracil-DNA glycosylase) (Invitrogen, USA), $4 \mathrm{mM} \mathrm{MgCl}_{2}, 0.5 \mu \mathrm{M}$ of each primer specific for the 18s rDNA gene of $T$. gondii TG III (5'-CCT TGG CCG ATA GGT CTA GG-3'); TG IIb (5'-GGC ATT CCT CGT TGA AGA TT-3'), and $180 \mathrm{nM}$ of the probe 5'-TGC AAT AAT CTA TCC CCA TCA CGA TGC ATA CTC AC-3' modified with 5'-FAM and 3'-TAMRA as reporter and quencher, respectively (Kupferschmidt et al., 2001). After initial UDG incubation for $2 \mathrm{~min}$ at $50^{\circ} \mathrm{C}$ and denaturation for $5 \mathrm{~min}$ at $95^{\circ} \mathrm{C}$, the two-step amplification conditions were 50 cycles of $20 \mathrm{~s}$ at $95^{\circ} \mathrm{C}$ and $60 \mathrm{~s}$ at $65^{\circ} \mathrm{C}$ with the LightCycler® 480 Real-Time PCR System (Roche Applied Science, Germany). A standard curve for parasite number equivalence was generated in parallel.

\subsection{Intestinal Permeability}

In vivo oral gavage with FITC-Dextran $4 k D a$ 
Mice received per oral gavage a solution of FITC-Dextran 4kDa (Sigma, St Quentin, France) at a concentration of $750 \mathrm{mg} / \mathrm{kg}$ of body weight. Intracardiac blood collection after opening of thoracic cavity was performed 4 hours after FITC-Dextran 4kDa gavage. FITC-Dextran 4kDa concentration in plasma was assessed by measuring the fluorescence intensity (FI) excitation 485nm / emission 525nm using an automatic Infinite M200 microplate reader (Tecan). Results were expressed as $\mu \mathrm{g}$ per ml of plasma.

\section{Ex vivo jejunal fragments mounted in Ussing chambers}

Jejunal fragments were mounted in Ussing chambers (Easy Mount, Physiologic Instruments) exposing a surface area measuring $0.1 \mathrm{~cm}^{2}$. They were bathed on each side with $1 \mathrm{ml}$ of oxygenated thermostated Kreb's solution (Sigma). Electrical parameters, including electrical resistance $(\mathrm{R})$, were recorded at regular intervals during the 2-hour period of experimentation. A change in electrical resistance was considered an index of altered paracellular permeability. Horseradish peroxidase ( $\mathrm{HRP} 44 \mathrm{kDa}$ ) (Sigma) transport was measured as an index of macromolecular permeability, and FSS (376Da) (Sigma) epithelial passage was measured as a marker of paracellular permeability to small molecules. After equilibration of electrical parameters, HRP was added to the mucosal compartment at a final concentration of 0.4 $\mathrm{mg} / \mathrm{ml}$, and FSS at a final concentration of $40 \mu \mathrm{g} / \mathrm{ml}$. The two markers were applied simultaneously in the mucosal compartment. Epithelial permeability to total HRP was determined by an ELISA. Briefly, 96-wells flat-bottomed black plates (Greiner, Thermo Scientific, Dutcher, Brumath, France) were coated overnight at $+4^{\circ} \mathrm{C}$ with $50 \mu 1$ of $10 \mu \mathrm{g} / \mathrm{ml}$ mouse polyclonal to HRP (Abcam) in PBS. Plates were blocked with PBS-1\% bovine serum albumin (BSA) before incubation with serosal compartments of Ussing chamber. Rabbit polyclonal anti HRP biotin (Abcam) was added at a concentration of $10 \mu \mathrm{g} / \mathrm{ml}$ before FITCconjugated streptavidin (Becton Dickinson; BD, Le Pont de Claix, France) was added for 20 minutes and fluorescence intensity measured $485 \mathrm{~nm} / 525 \mathrm{~nm}$ using an automatic Infinite M200 
microplate reader (Tecan). Epithelial permeability to FSS was determined by measuring the fluorescence intensity (FI) 485nm/525nm using an automatic Infinite M200 microplate reader (Tecan). Permeability was calculated as the ratio of flux/concentration, and expressed as $\mathrm{cm} /$ second.

\subsection{Visceral sensitivity in response to colorectal distension}

Mice were anesthetized with a mixture of ketamine $100 \mathrm{mg} / \mathrm{kg}$ of body weight and xylazine $10 \mathrm{mg} / \mathrm{kg}$ of body weight, equipped with $3 \mathrm{NiCr}$ wire electrodes implanted into the abdominal external oblique muscle at D47 and kept individually after surgery. The electromyographic (EMG) activity was recorded and analyzed with a Powerlab Chart from AD instrument. EMG recordings began 3 days after surgery. Mice were placed in polypropylene tunnels. A balloon consisting of an arterial embolectomy catheter (Fogarty, 4F, Edwards Laboratories, Santa Ana, CA) was introduced into the rectum at $2.5 \mathrm{~cm}$ from the anus and fixed at the base of the tail. The balloon was progressively inflated during 15 seconds by step of $0.02 \mathrm{ml}$, from 0.02 to $0.1 \mathrm{ml}$, with 10 minutes wait between each step. The Fogarty embolectomy catheter balloon was calibrated using an electronic caliper gauge and the maximal pressure applied (corresponding to $0.1 \mathrm{ml}$ ) was calculated as $63.1 \pm 1.7 \mathrm{mmHg}$ meaning that volume progressive distension corresponds to a range of pressures between 0 and $63.1 \pm 1.7 \mathrm{mmHg}$. Basal EMG activity was subtracted from the EMG activity registered during the periods of distension. The use of Forgaty probe and volumes rather than barostat and pressures was selected to obtain reliable VMR at low volumes.

\subsection{Enteric lysozyme analysis}


Ileal samples were fixed in $4 \%$ formalin, dehydrated through graded ethanol and embedded in paraffin. Sections $(5 \mu \mathrm{m})$ were rehydrated and submerged in antigen retrieval solution (citrate buffer, $10 \mathrm{mM}, \mathrm{pH} 6,99^{\circ} \mathrm{C}$ ) for 30 minutes. After incubation in blocking solution (PBS $0,01 \%$ Tween 20, $1 \%$ bovine serum albumin and $2 \%$ donkey normal serum) for $15 \mathrm{~min}$, sections were incubated with rabbit anti-mouse lysozyme antibody $\left(1 / 100\right.$, overnight, $\left.+4^{\circ} \mathrm{C}\right)(\mathrm{Abcam}$, Paris, France) followed by a Alexa fluor 488-conjugated donkey anti-rabbit IgG $(0.75 \mu \mathrm{g} / \mathrm{ml}$, 1H, Room temperature) (Jackson, Sullfolk, UK). After washing, sections were incubated with Alexa fluor 594-conjugated Wheat Germ Agglutinin (WGA) $(10 \mu \mathrm{g} / \mathrm{ml}, 45 \mathrm{~min})$ (Invitrogen, Life Technology, Cergy Pontoise, France). Sections were mounted in Prolong gold antifade mounting medium with DAPI (Invitrogen) and examined under a Nikon 90i fluorescence microscope. Lysozyme fluorescence intensity in Paneth cells was quantified employing the software Nis-Elements Ar (Nikon, Champigny sur Marne, France) and results were expressed in fluorescence intensity per cell. Analyses were done on five crypts per animal and on five animals from each group.

\section{Lysozyme activity in fecal content}

Feces were collected and frozen at $-80^{\circ} \mathrm{C}$. Activity of lysozyme against the peptidoglycan was determined using the EnzChek® Lysozyme Assay Kit (Molecular probes, life technology, St Aubin, France).

\subsection{Fecal microbiota composition analysis}

Total community DNA was extracted from stool samples and adjusted to $1 \mathrm{ng} / \mu \mathrm{l}$ prior to use as described in (Yvon et al., 2016). Changes in the relative abundance of 20 relevant microbial 16S rRNA gene targets (supplementary table) were obtained using the GULDA 
platform approach (Bergström et al., 2014, 2012) with minor adaptations (Yvon et al., 2016). The normalized No-values were reported per g feces, log10-transformed and processed by MixOmics package (5.2.0 version) with RStudio software (0.99.902 version) to build a partial least-squares discriminant analysis (PLS-DA) (dejean omics data integration project. $\mathrm{R}$ package version 2012). PLS-DA is a multivariate supervised approach that operates by projecting the samples $(\mathrm{X})$ onto a low-dimensional space of so-called latent variables that maximizes the separation between different groups of samples according to their class labels (Y= mouse treatments). Missing normalized No-values were reconstituted using the NIPALS algorithm and leave-one-out cross-validation was used to select the optimal number of latent variables for PLS-DA models with minimal error rate. Variable Importance in Projection (VIP, weighted sum of squares of the PLS loadings) scores were estimated and allowed to classify the microbial amplicon groups according to their explanatory power of class label (Tenenhaus, 1998).

\section{$2.6{ }^{1} \mathrm{H}$ NMR metabolomics and data analysis}

Fecal extracts for NMR spectroscopy were prepared by mixing $50 \mathrm{mg}$ of fecal samples with $500 \mu \mathrm{L}$ of phosphate buffer $(0.2 \mathrm{M}, \mathrm{pH}=7.4)$ in $\mathrm{D} 2 \mathrm{O}$, containing $1 \%(\mathrm{w} / \mathrm{v})$ of sodium 3(trimethylsilyl) propionate (TSP). After vortex mixing, the samples were subjected to a freeze-thaw cycle in liquid nitrogen and subsequently homogenized with a tissue lyser (MP Biomedicals, Illkirch Graffenstaden, France) at $20 \mathrm{~Hz}$ during $40 \mathrm{~s}$, followed by centrifugation at $10000 \mathrm{~g}$ for $10 \mathrm{~min}$ at $4{ }^{\circ} \mathrm{C}$. Supernatants were collected, and the remaining pellet was further extracted once as described above. Supernatants obtained from two runs of extraction were combined and centrifuged at $10000 \mathrm{~g}$ for $10 \mathrm{~min}$ at $4{ }^{\circ} \mathrm{C}$. A total of $600 \mu \mathrm{L}$ of supernatant was transferred into NMR tubes with an outer diameter of $5 \mathrm{~mm}$ pending NMR analysis. 
All ${ }^{1} \mathrm{H}$ NMR spectra were obtained on a Bruker DRX-600-Avance NMR spectrometer (Bruker, Wissembourg, France) operating at $600.13 \mathrm{MHz}$ for ${ }^{1} \mathrm{H}$ resonance frequency using an inverse detection $5 \mathrm{~mm} 1 \mathrm{H}-13 \mathrm{C}-15 \mathrm{~N}$ cryoprobe attached to a cryoplatform (the preamplifier cooling unit). The ${ }^{1} \mathrm{H}$ NMR spectra were acquired at $300 \mathrm{~K}$ using the CarrPurcell-Meiboom-Gill (CPMG) spin-echo pulse sequence with water presaturation. A total of 128 transients were collected into 64,000 data points using a spectral width of $20 \mathrm{ppm}$, a relaxation delay of $2 \mathrm{sec}$, and an acquisition time of $2.72 \mathrm{sec}$. Metabolites were assigned using previously published data (Zhao et al., 2012) and additional two-dimensional NMR experiments on selected samples.

Data were analyzed by applying an exponential window function with a line broadening of $0.3 \mathrm{~Hz}$ prior to Fourier transformation. The resultant spectra were phased, baseline corrected and calibrated to TSP $(\delta 0.00)$ manually using Mnova (Mestrelab Research S.L.). The spectra were subsequently imported into MatLab (R2014a, The MathsWorks inc.). All data were analyzed on full-resolution spectra (33 600 data points). The region containing the water resonance $(\delta$ 4.6-5.2) was removed. Spectra were normalized to the probabilistic quotient (Dieterle et al., 2006) and aligned using an alignment function (Veselkov et al., 2009). Data were mean-centred and scaled using the unit variance scaling prior to analysis with orthogonal projection on latent structure-discriminant analysis (O-PLS-DA). ${ }^{1} \mathrm{H}$ NMR data were used as independent variables ( $\mathrm{X}$ matrix) and regressed against a dummy matrix ( $\mathrm{Y}$ matrix) indicating the class of samples (control or MS) (Trygg and Wold, 2002). The O-PLSderived model was evaluated for goodness of prediction $\left(Q^{2} \mathrm{Y}\right.$ value $)$ using 8-fold crossvalidation. The reliability of each model was established using a permutation test of the Y vector (1000 permutations) to determine a $\mathrm{p}$-value for each $\mathrm{Q}^{2} \mathrm{Y}$, as previously described (Eriksson et al., 2008). Parameters of the final models are indicated in the figure legends. 
To identify metabolites discriminating the animal groups, the O-PLS-DA correlation coefficients $\left(\mathrm{r}^{2}\right)$ were calculated for each variable and back-scaled into a spectral domain, so that the shape of the NMR spectra and the sign of the coefficients were preserved (Cloarec et al., 2005). The weights of the variables were color-coded according to the square of the OPLS-DA correlation coefficients. Correlation coefficients extracted from significant models were filtered so that only significant correlations above the threshold defined by Pearson's critical correlation coefficient $(\mathrm{p}<0.05 ;|\mathrm{r}|>0.49)$ were considered significant. For illustration purposes, the area under the curve of several signals of interest was integrated, and statistical significance was tested using Mann-Whitney test.

\subsection{Spleen and Lamina propria cell characterization}

\section{Splenocyte isolation}

Spleens were removed and cells were isolated through a $70 \mu \mathrm{m}$ nylon mesh in PBS/1\% $\mathrm{KnockOut}^{\mathrm{TM}}$ SR (KO SR) (GIBCO). Splenocytes were stained with antibodies to the following markers: anti-CD4 (BD), anti-CD44 (BD), anti-CD62L (BD), anti-CD25 (BD), anti-foxp3 (ebioscience, Rennes, France) prior analysis by flow cytometry.

Small intestines were washed in cold PBS, cut into $0.5 \mathrm{~cm}$ pieces, incubated four times in 30 $\mathrm{ml}$ of PBS-3 mM EDTA (Sigma) for $10 \mathrm{~min}$ at $37^{\circ} \mathrm{C}$ and digested in $30 \mathrm{ml}$ of RPMI 1640 added with $20 \% \mathrm{BSA}$ and $100 \mathrm{U} / \mathrm{mL}$ of collagenase (Sigma) for $40 \mathrm{~min}$ at $37^{\circ} \mathrm{C}$. Lamina propria cells were purified on a 40\%-80\% Percoll gradient run for $15 \mathrm{~min}$ at 2,000g and cells were stained with anti-MHC II and anti-ROR $\gamma \mathrm{t}$ antibodies (BD).

Flow cytometry data collection was performed on MACSQuant ${ }^{\circledR}$ Analyzers (Miltenyi Biotec, Paris, France). Data were analysed using VenturiOne ${ }^{\circledR}$ (AplliedCytometry) software.

\section{Measurement of splenocytes activation}


After washing, cells were seeded on 24 -well plates at $1 \times 10^{6}$ cells per well for cytokines assays in Cerrotini culture medium (Dulbecco modified Eagle medium supplemented with $8 \% \mathrm{KO}$ SR (GIBCO), $36 \mathrm{mg} / \mathrm{l}$ asparagine, $116 \mathrm{mg} / 1$ arginine, $10 \mathrm{mg} / \mathrm{l}$ folic acid, $1 \mathrm{~g} / \mathrm{l} \mathrm{4-[2-}$ hydroxyethyl]-1-piperazineethanesulfonic acid, $0.05 \mathrm{mmol} / 1 \quad \beta$-mercaptoethanol, $100 \mathrm{U} / \mathrm{ml}$ penicillin, $100 \mathrm{Kg} / \mathrm{ml}$ streptomycin and $1 \mu \mathrm{g} / \mathrm{ml}$ fungizone) in the presence or absence of $5 \mu \mathrm{g} / \mathrm{ml}$ hamster anti-mouse CD3 and hamster anti-mouse CD28 (BD) coated wells. After 3 days of stimulation, culture supernatants were collected and frozen at $-80^{\circ} \mathrm{C}$ prior cytokines measurement.

\subsection{Cytokine measurement}

Cytokines were measured in supernatant of primary cell culture of spleen, on ileal fragments or in feces previously treated as follow. Frozen ileal fragments or feces were suspended in RIPA buffer $(0.5 \%$ deoxycholate, $0.1 \%$ SDS and $1 \%$ Igepal in TBS) containing complete anti protease cocktail (Roche), protein concentrations were measured using BCA uptima kit (Interchim).

$\mathrm{TNF} \alpha, \mathrm{IFN} \gamma, \mathrm{TGF} \beta$ or lipocalin present in primary cell culture supernatant, ileal tissues or feces were assayed using commercial enzyme linked immunosorbent assays (ELISA kits; Duoset R\&D Systems, Lille, France). Concentration of TNF $\alpha$ in ileal tissue and lipocalin in feces were normalized per mg of proteins and results expressed in pg of cytokine per $\mathrm{mg}$ of proteins.

\subsection{Commensal E. coli and food lysate preparations}

E. coli lysate for humoral response 
Pellet of an overnight culture of one of the E. coli isolates previously characterized (Riba et al., 2017) was washed in $0,9 \% \mathrm{NaCl}$, suspended in $1 \mathrm{ml}$ of distilled water, sonicated for 1 hour, frozen in liquid nitrogen, melt and centrifuged. Supernatant was filtered in $0,22 \mu \mathrm{m}$ and conserved at $-20^{\circ} \mathrm{C}$ as the $E$. coli lysate used for humoral and cellular response. Lysate protein concentration was measured using BCA (bicinchoninic acid) protein Assay kit, Uptima (Interchim, Montluçon, France).

Food lysate for humoral response

Food was suspended in PBS, incubated and vortexed. Supernatant was filtered on $0.22 \mu \mathrm{m}$ filter and kept at $-20^{\circ} \mathrm{C}$ as the food lysate used for humoral response. Lysate protein concentration was measured using BCA protein Assay kit, Uptima (Interchim, Montluçon, France).

\subsection{Humoral response in plasma and feces.}

Intracardiac blood was recovered with heparined needle and plasma was kept at $-80^{\circ} \mathrm{C}$.

Fecal proteins were extracted mechanically in complete antiprotease cocktail (Roche Diagnostic, Meylan, France) and frozen at $-80^{\circ} \mathrm{C}$.

\section{Quantification of $\operatorname{Ig} G$ and $\operatorname{IgA}$ concentrations}

Plasma and fecal IgG or IgA concentrations were measured by ELISA in MaxiSorp 96-wells flat-bottomed plates (NUNC, Thermo Scientific, Dutcher, Brumath, France). Plates were coated overnight at $+4{ }^{\circ} \mathrm{C}$ with $50 \mu 1$ of $5 \mu \mathrm{g} / \mathrm{ml}$ sheep anti-mouse IgA (Sigma) or goat anti-mouse IgG (SoutherBiotech, Cliniscience, Nanterre, France) in PBS. Plates were blocked with PBS-5\% fetal calf serum (FCS) (GIBCO, Invitrogen, Life Technology, St Aubin, 
France) before incubation with diluted samples or purified IgA or IgG (SoutherBiotech). Plasma was diluted at 1:20,000 for IgG and fecal extracts at 1:6,000 for IgA. Horseradishperoxidase (HRP)-conjugated goat anti-mouse IgA (Sigma) or goat anti-mouse IgG (SoutherBiotech) were added, HRP was revealed using TMB (Becton Dickinson; BD, Le Pont de Claix, France) and the reaction was stopped with $25 \mu$ of $\mathrm{H}_{2} \mathrm{SO}_{4} 2 \mathrm{~N}$ before reading at 450 nm using an automatic Infinite M200 microplate reader (Tecan). Results were expressed as $\mu \mathrm{g} / \mathrm{ml}$ for plasma and $\mu \mathrm{g} / \mathrm{mg}$ of fecal proteins for IgA.

\section{Immunoglobulin specificity against luminal content}

Maxisorp 96-well plates (NUNC) were coated overnight at $+4^{\circ} \mathrm{C}$ with $50 \mu 1$ of a) $5 \mu \mathrm{g} / \mathrm{ml}$ of E. coli lysate or b) $20 \mu \mathrm{g} / \mathrm{ml}$ of food lysate. After blocking with PBS 5\%-FCS, plates were incubated for 2 hours at $37^{\circ} \mathrm{C}$ with $50 \mu$ of plasma samples diluted with PBS $5 \%$-FCS to adjust IgG concentration to $20 \mu \mathrm{g} / \mathrm{ml}$. HRP-conjugated goat anti-mouse IgG (SoutherBiotech) was incubated for 2 hours at $37^{\circ} \mathrm{C}$ and revealed as above-mentioned. Results were expressed as optical density (OD) at $450 \mathrm{~nm}$ and were considered positive if above two blanks.

\subsection{Histology}

Colon samples were collected, fixed with $10 \%$ formalin for $24 \mathrm{~h}$, dehydrated and embedded in paraffin according to standard histological procedures. Sections $(5 \mu \mathrm{m})$ were mounted on SuperFrost ${ }^{\circledR}$ Plus Slides then dewaxed in a xylene bath for 10 min and rehydrated in graded alcohol baths. Slides were stained with hematoxylin and eosin (H\&E) and analyzed for intestinal morphometry. Erben and el. histomorphological scoring was used (Erben et al., 2014).

\subsection{Statistical analysis}


Statistical analysis was performed using GraphPad Prism version 6.04 (GraphPad Software,

San Diego, California, USA). Results were expressed as box and whisker plots. Mean comparisons were performed using two-way ANOVA analysis followed by post test or t tests. Differences were considered significant for $\mathrm{p}<0.05$. 


\section{Results}

Of note, no difference in weight was observed between control and stressed mice.

\subsection{MS increased intestinal permeability and visceral sensitivity to colorectal distention}

MS significantly increased in vivo intestinal permeability to FITC-Dextran 4kDa at D50 $\left(17.76 \pm 1.18\right.$ vs. $8.09 \pm 0.79 \mu \mathrm{g} / \mathrm{ml}$ of plasma, $\mathrm{t}_{10}=2.275 \mathrm{p}=0.0462$ Two-tail $\mathrm{t}$-Test, , Figure $\left.1 \mathrm{~A}\right)$. MS also significantly increased ex vivo transcellular permeability to HRP (4.168 \pm 0.7273 vs. $2.542 \pm 0.198 \mathrm{~cm} / \mathrm{s} .10^{-8} \mathrm{t}_{18}=2.158 \mathrm{p}=0.0447$, Two-tail $\mathrm{t}$-Test) but not para cellular permeability to FSS in jejunal fragments mounted in Ussing chambers (Figure 1B). Furthermore, MS increased visceral sensitivity to colorectal distention at low volumes $(3.99 \pm 0.59$ vs. $0.9 \pm 0.1$ mV.s at $0.02 \mathrm{ml} ; 5.24 \pm 1.06$ vs. $2.03 \pm 0.44 \mathrm{mV}$.s at $0,04 \mathrm{ml} ; 6.34 \pm 0.87$ vs. $3.07 \pm 0.62 \mathrm{mV} . \mathrm{s}$ at $0.06 \mathrm{ml}$ compared to control $\mathrm{p}<0.05$, MS versus control $\mathrm{F}_{4,141}=2.158, \mathrm{p}<0.0001$ Two-way ANOVA followed by Holm-Sidak's post test) (Figure 1C). This result reflects MS-induced allodynia i.e. pain response at non nociceptive stimulation.

\subsection{MS decreased ileal expression and fecal activity of lysozyme}

Production of antimicrobial compounds by Paneth cells represents an important defense mechanism of the epithelium and shapes intestinal microbiota. MS decreased ileal expression of lysozyme in Paneth cells $(65803 \pm 17448$ vs.160960 \pm 27224 fluorescence intensity/cell, $\mathrm{t}_{6}=2.943 \mathrm{p}=0.0259$ Two-tail $\mathrm{t}$-Test $)$ without modification of the number of crypts producing lysozyme (Figures 2A-C). Moreover, fecal anti-peptidoglycan activity of lysozyme was decreased in MS mice compared to controls $(155.5 \pm 35.28$ vs. $332.2 \pm 45.43 \mathrm{U} / \mathrm{mg}$ of fecal proteins $\mathrm{t}_{23}=3.099, \mathrm{p}=0.0051$ Two-tail $\mathrm{t}$-Test, Figure $2 \mathrm{D}$ ). The defect of lysozyme expression 
in ileal Paneth cells was associated with higher TNF $\alpha$ concentration in ileum $(13.7 \pm 2.47$ vs. $6 \pm 1.17 \mathrm{pg} / \mathrm{mg}$ of proteins, $\mathrm{t}_{11}=2.653, \mathrm{p}=0.0225$ Two-tail $\mathrm{t}$-Test) (Figure 2E).

\subsection{MS induced fecal microbiota dysbiosis associated with bile acid malabsorption.}

We next investigated if the alterations of intestinal barrier functions induced by MS resulted from a change in microbiota composition. A score plot of PLS-DA built from the relative quantitative abundances of the 20 phyla/groups/taxa or species analyzed, showed a clear separation of mouse microbiota according to stress exposure. Based on the variable importance on projection (VIP) of the PLS-DA model, a decrease of Bifidobacterium spp., Eubacterium hallii and Roseburia spp. associated with an increase of Clostridium butyricum and Desulfovibrio spp. were selected as the 5 most important bacterial contributors that characterize the fecal bacterial profile of MS group (Figure 3A).

We then used ${ }^{1} \mathrm{H}-\mathrm{NMR}$-based metabolomics to further investigate differences in metabolic activity of gut microbiota in feces from MS and control. The fecal metabolome of the mice comprised many metabolites derived from the host-microbiota co-metabolism such as shortchain fatty acids (propionate, succinate, acetate), amino acids (leucine, valine, isoleucine...), keto-acids (5-aminovalerate...) and bile acids among others (Supplementary Figure $1 \mathrm{~A}$ and B). MS significantly increased the fecal cholic acid content $\left(\mathrm{t}_{14}=4.537, \mathrm{p}=0.0005\right.$ Two-tail $\mathrm{t}-$ Test) and decreased the fecal lactate content $\left(\mathrm{t}_{14}=2.649 \mathrm{p}=0.0191\right.$ Two-tail $\mathrm{t}$-Test) (Figure 3BC).

3.4 MS increased IgA in feces but decreased ILC3 in lamina propria associated with increased IgG against microbial components 
Beside intestinal epithelium and microbiota intestinal barrier is also composed of immune factors. Therefore, we focused on the changes in mucosal and systemic immunity following MS. MS increased IgA in feces $\left(\mathrm{t}_{20}=3.686 \mathrm{p}=0.0015\right.$ Two-tail t-Test, Figure $\left.4 \mathrm{~A}\right)$. MS decreased ILC3 $\left(\mathrm{MHCII}^{+}\right.$, ROR $\left.\gamma \mathrm{t}^{+}\right)$percentage in the lamina propria of the small intestine $\left(0.41 \pm 0.003 \%\right.$ vs. $0.74 \pm 0.12 \%, \mathrm{t}_{8}=3.109, \mathrm{p}=0.0145$ Two-tail $\mathrm{t}$-Test, Figure $\left.4 \mathrm{~B}\right) . \mathrm{MS}$ did not induce any modifications of total IgG concentration in plasma (Figure 4C). However, decrease of ILC3 was associated with an increase of anti-E. coli IgG in plasma $(0.046 \pm 0.012$ vs. $0.035 \pm 0.012$ OD450nm, $\mathrm{t}_{20}=3.686, \mathrm{p}=0.0015$ Two-tail $\mathrm{t}$-Test)Figure $4 \mathrm{D}$ ) but not $\mathrm{IgG}$ directed against hydrosoluble food antigens (Figure 4E).

\subsection{MS altered T cell populations and functionality in spleen}

MS induced splenomegaly (Supplementary Figure 2). A detailed analysis of splenocyte populations showed that $\mathrm{MS}$ increased the percentage of $\mathrm{CD} 4{ }^{+} \mathrm{CD} 44^{\text {high }} \mathrm{CD} 62 \mathrm{~L}^{\text {low }}$ activated T lymphocytes $\left(13.8 \pm 0.4 \%\right.$ vs. $12.4 \pm 0.4 \%, \mathrm{t}_{21}=2.542 \mathrm{p}=0.019$ Two-tail $\mathrm{t}-$ Test, Figure $\left.5 \mathrm{~A}\right)$ and decreased the percentage of $\mathrm{CD} 4^{+} \mathrm{CD} 25^{+}$Foxp $^{+}$regulatory $\mathrm{T}$ lymphocytes $(1.07 \pm 0.08$ vs. $1.35 \pm 0.06 \%, \mathrm{t}_{7}=2.7, \mathrm{p}=0.0306$, Two-tail $\mathrm{t}$-Test, Figure $\left.5 \mathrm{~B}\right)$. We next investigated functionality of $\mathrm{T}$ lymphocytes by anti-CD3/CD28 stimulation. Without stimulation, MS modified neither IFN $\gamma$ nor TGF $\beta$ secretion by splenocytes (Figures 5C-D). Anti-CD3/CD28 antibody stimulation induced similar levels of TGF $\beta$ secretion in both controls and MS mice but significantly higher IFN $\gamma$ secretion in MS mice $\left(\mathrm{F}_{1,11}=5.042 \mathrm{p}=0.0463 \mathrm{MS}\right.$ versus control Two-way ANOVA followed by Holm-Sidak's post test Figure 5C-D). In summary, MS not only altered splenic $\mathrm{T}$ cell populations but also their functionality. 


\subsection{MS did not precipitate nor exacerbate colitis in $I L 10^{-/-}$C57BL/6 genetically predisposed mice.}

As we showed that MS induced intestinal barrier impairment associated with systemic immune response, we then wondered if MS could precipitate or worsen colitis in genetically predisposed mice, housed on SOPF sanitary status. At PND170, IL10 ${ }^{-/-}$mice that were exposed to MS had a non-significant reduction in weight gain compared to control IL10 ${ }^{-/-}$ mice (Figure 6A). We analyzed further the consequences of MS on colitis features on IL10 ${ }^{-/-}$ mice. We observed no significant decrease of colon length (Figure 6B), no increase of histology damage score (Figure 6C) nor lipocalin (fecal marker for inflammation) concentration in feces (figure 6D) in MS mice compared to control.

\subsection{MS did not induce susceptibility to gastrointestinal infections}

Finally, we investigated if the consequences of MS on intestinal barrier function and systemic immune response might impair the defense against pathogens known to enter the host via the intestine. Three enteric pathogens were evaluated: Salmonella Typhymurium, Listeria monocytogenes and Toxoplasma gondii. Samonella Typhymurium and Listeria monocytogenes are bacteria whereas Toxoplasma gondii is a parasite. Both Listeria monocytogenes and Toxoplama gondii are intracellular pathogens whereas Salmonella Typhymurium is a facultative intracellular bacterium. Infection was confirmed by measuring bacterial/parasite titers in liver, spleen and MLN. However, MS had no effect on mouse weight nor on bacterial (S. typhimurium or L. monocytogenes) burden in small intestine, liver or spleen or T. gondii parasite load in the ileum or MLN (Figure 7). 


\section{Discussion}

Previous studies in rats demonstrated that MS increased intestinal permeability (Barreau et al., 2004) or visceral sensitivity (Barreau et al., 2004) to colorectal distension in young-adults. Other studies revealed an increased permeability in response to MS in mice (Varghese et al., 2006). However, to our knowledge, this study described for the first time an experimental model of male mice reproducing all main features of IBS: visceral hypersensitivity, intestinal hyperpermeability, microbiota changes, activated immune system and bile acid malabsorption.

A comparative study showed that MS increased visceral sensitivity in both male and female rats with a higher visceral sensitivity in male submitted to MS at PND56 (Yi et al., 2017). In our study, male mice were used to avoid female hormonal cycle interference. Also in rats previous work of our laboratory in rats demonstrated that nerve growth factor induced by MS was responsible for visceral hypersensitivity and intestinal hyperpermeability (Barreau et al., 2004). The same mechanism may apply in mice but this needs to be further investigated. Instead, in this study, we further characterized the consequences of early life stress on male mice on factors contributing to intestinal barrier integrity. MS decreased lysozyme expression in Paneth cells and its antimicrobial activity. This defect of lysozyme is associated with microbiota dysbiosis characterized by a decrease of health associated Bifidobacteria spp., E. hallii and Roseburia spp.. Interestingly, Bifidobacteria were decreased in IBS patients (Rajilić-Stojanović et al., 2011). In addition, MS induces an increase in fecal cholic acid, thereby mimicking the bile acid malabsorption described in IBS patients (Peleman et al., 2017; Shin et al., 2013). This defect in bile acid absorption could be linked to microbiota dysbiosis as both Bifidobacterium spp. and Eubacterium spp. are involved in bile acid metabolism (Gérard, 2013). In addition, MS increased TNF $\alpha$ production in the ileum that 
might trigger and/or maintain the increase of intestinal permeability (Gitter et al., 2000) and Paneth cell dysfunction (Van Hauwermeiren et al., 2014).

Furthermore, MS induced a decrease of $\mathrm{ROR} \gamma \mathrm{t}^{+} \mathrm{MHCII}^{+} \mathrm{ILC} 3$ cells in lamina propria associated with increase $\operatorname{IgG}$ response toward microbiota, E. coli lysate being used as representative bacteria of the intestinal microbiota. Those results are in accordance with literature showing that ILC3 contain immune response toward bacteria locally (Hepworth et al., 2013; Sonnenberg et al., 2012).

Interestingly, increase of antibodies toward bacterial antigens was described in IBS plasma samples (Cremon et al., 2008; Schoepfer et al., 2008). Furthermore, stress during childhood was associated with higher antibody titers against cytomegalovirus (Dowd et al., 2012), herpes simplex virus-1 (Shirtcliff et al., 2009) and Epstein-Barr Virus (Slopen et al., 2013). As an increase in intestinal trans-cellular permeability was observed, one can speculate that higher amounts of bacterial antigens may cross the intestinal epithelium of MS mice and affect the immune response. Interestingly, a defective intestinal barrier led to increased humoral response toward colibiota but not food antigens, in line with the recent observation reported by Frehn et al in IBD (Frehn et al., 2014), which excludes a general loss of tolerance toward luminal content as observed in our model.

MS induced splenomegaly was associated with an increase of activated $\mathrm{T}$ cells $\left(\mathrm{CD} 4{ }^{+} \mathrm{CD} 44^{\text {high }} \mathrm{CD}^{2} \mathrm{~L}^{\text {low }}\right)$ and a decrease of regulatory T cells (Treg) $\left(\mathrm{CD} 4^{+} \mathrm{CD} 25^{+} \mathrm{Foxp}^{+}\right)$. Bifidobacteria which are decreased in MS mice, are known to markedly induce Foxp $3^{+}$Treg in mice (O'Mahony et al., 2008). Those changes in T cell populations were associated with functional modifications as reflected by the increase in IFN $\gamma$ secretion by splenocytes after anti-CD3/CD28 stimulation. This increase in the pro-inflammatory profile of $\mathrm{T}$ cells can be a consequence of bacterial translocation occurring during the neonatal period when maternal 
separation was applied. In agreement with this, repeated stress during neonatal period in mice is associated with long-term release of IFN $\gamma$ by splenocytes in later life (Loizzo et al., 2002). In IBS, anti-CD3/CD28 stimulation of PBMC also induced a pro-inflammatory profile as reflected by higher amount of pro-inflammatory cytokine IL1 $\beta$ compared to controls (Ohman et al., 2009). Only one paper studied Treg in IBS but did not observe any modifications (Holmen et al., 2007). Nevertheless, further investigations are needed to better understand a potential role of Treg in IBS physiopathology.

Interestingly, both intestinal hyperpermeability and visceral hypersensitivity induced in adult after MS in early life and observed herein are common features of IBS and IBD pathophysiology (Halpin and Ford, 2012; Piche et al., 2009; Wyatt et al., 1993). Furthermore, an increase of antibodies against bacterial antigens was not only observed in IBS plasma samples (Cremon et al., 2008; Schoepfer et al., 2008) but also in CD patients (Landers et al., 2002; Lodes et al., 2004). Finally, a defect of antimicrobial peptides production by Paneth cells has been described in CD patients (HD5) (Wehkamp, 2005) and is observed in mice submitted to MS. All those similarity between MS mouse model and CD questioned a potential role of MS in triggering or exacerbating colitis in mice genetically predisposed. The $\mathrm{IL}_{10}{ }^{-/}$mouse is a well-described model of IBD that develops spontaneous Crohn's diseaselike intestinal inflammation in the presence of conventional intestinal microbiota (Schultz et al., 2002; Sellon et al., 1998) but develop a mild, patchy colitis with incomplete disease penetrance under SOPF conditions (Berg et al., 1996). Therefore, IL10 ${ }^{-/-}$in SOPF represents an ideal model to study the role of MS on the initiation and exacerbation of colitis. In this model, MS did not precipitate nor exacerbate colitis suggesting that the observed defect of intestinal barrier and immune response is not sufficient to induce a breach in intestinal defense and predispose the mice to colitis. However, in IL10 $0^{-/-}$mice under conventional sanitary status, Lennon and al demonstrated that a longer MS protocol (18 days) does not 
induce but exacerbates the severity of colitis in 10-12 weeks old mice (Lennon et al., 2013) suggesting that MS alone is not sufficient to increase colitis but is a risk factor factor under conventional sanitary status. Our results are in accordance with epidemiological studies (Bonaz and Bernstein, 2013; Shiga et al., 2013) and experimental studies (Lennon et al., 2013; Schultz et al., 2015) showing that stress does not induce de novo IBD. A susceptibility of IBS patients to develop IBD, especially $\mathrm{CD}$, has been suggested but only in case of Post Infectious (PI)-IBS (Gradel et al., 2009; Porter et al., 2012; Ternhag et al., 2008). In addition to genetic models of IBD, much of the research concerning the role of stress in intestinal inflammation has been conducted in chemically-induced models and shows an aggravation of colitis following stress (Barreau et al., 2004; Maunder, 2000; Qiu et al., 1999). Although the oral or rectal administration of different chemicals reliably induces colitis, the administration itself is a stressor adding to the several shortcomings of these models in the study of stress on intestinal inflammation.

Even though MS could not trigger nor worsen colitis in IL10 ${ }^{-/-}$mice, it did not mean that it had no consequences on host defense against gastrointestinal infection. MS did not increase susceptibility to L. monocytogenes, S. Typhimurium or T. gondii infections inoculated orally. Previous studies showed that rats submitted to perinatal MS are more susceptible to $N$. brasiliensis infection at adulthood. However, the inoculation route was systemic (subcutaneous) and not intestinal (Barreau et al., 2006). It has been well described that MS in mice induced a more rapid onset and a more severe sickness to influenza virus (Avitsur et al., 2015). However, evidence is lacking on the influence of stress on enteric infections. Our study is of particular interest in the context of epidemiological studies in humans. Indeed, psychosocial stress is associated with increased viral load in HIV and HPV (Ironson et al., 2005; Lu et al., 2016) as well as elevated risk of diagnosis or severity of other infections (upper and lower respiratory tract) (Biondi and Zannino, 1997; Cohen et al., 2012). 
Nevertheless, there was either inverse or no association of stress with enteric infections (Melinder et al., 2017).

\section{Conclusion}

Altogether, our results identify MS in mice as a suitable experimental model for IBS including all the main features i.e. intestinal hyperpermeability, visceral hypersensitivity, microbiota dysbiosis, bile acid malabsorption and low grade inflammation. In addition, even though they have long lasting consequences on intestinal homeostasis early life events do not constitute a sufficient risk factor for colitis in genetically predisposed mice nor to gastrointestinal infections in wild type mice. This observation is in accordance with epidemiological studies showing that only post infectious IBS are at risk to develop IBD and that stress does not induce de novo IBD. Therefore, it appears that early life stress does not induce a detrimental effect on the organism, and preserves its ability to cope with intestinal challenges.

\section{Acknowledgements}

We thank the staff members of the following core facilities for technical assistance: MetaToul-AXIOM/metabolomic (R. Gautier, C. Canlet and M. Tremblay-Franco), M2C/imaging (T. Gauthier), TRiX/transcriptomic (Y. Lippi and C. Naylies) and EZOP/animal facilities (E. Jeunesse), Infectious facilities (V. Dupouy).

We also acknowledge Isabelle Dimier-Poisson (Immunologie Parasitaire et Vaccinologie, Biothérapies Anti-Infectieuses, Université de Tours-INRA, UMR1282 Infectiologie et Santé Publique, UFR Pharmacie, F-37000 Tours, France) for providing T. gondii inoculum. 
Finally, we acknowledge Dr Vuk Cerovic for proofreading and improvement of the manuscript.

\section{Funding}

This work was supported by Cephalon

\section{Author contributions}

Conceived and designed the experiments: AR, SM

Performed the experiments: AR, MO, SLL, CL, VB, CH, NVL, MG, CC, MB, CS, VM, MZ, HR, SES, SM

Analyzed the data. Contributed materials/analysis tools: AR, MO, SLL, SES, SM

Wrote the paper: MO, SLL, FL, VT, SM

\section{Conflict of interest}

The authors declare no conflict of interest. 


\section{REFERENCES}

\section{LEGENDS}

Figure 1: Effects of Maternal Separation (MS) in mice on Intestinal Permeability to various markers and visceral sensitivity in young-adult male mice. (A) Representative box plots of Dextran-FITC 4kDa (FD4) concentration measured in plasma 4 hours after gavage, in MS group (grey histogram) and control group (white histogram) ( $\mathrm{n}=6$ mice per group) $* \mathrm{p}<0.05$ compared to control mice (Mann-Whitney) (B) jejunal permeability of Horse Radish Peroxidase (HRP) or Fluorescein Sodium Salt (FSS) measured after 2H bathing in Ussing chambers in MS group (grey) and control group (white) ( $\mathrm{n}=10$ to 14 mice per group) ${ }^{*} \mathrm{p}<0.05$ compared to control mice (Mann-Whitney). (C) Representative curves of abdominal contractions in response to colorectal distension with increasing volumes $(0.02$ to $0.1 \mathrm{ml})$ in MS (grey scares plain line) compared to control (white circles dashed line) ( $\mathrm{n}=17$ to 19 mice per group). ${ }^{*} \mathrm{p}<0,05$ compared to identical volumes for controls (Two-way ANOVA followed by Holm-Sidak's post-test).

Figure 2: Lysozyme expression and activity. (A) Immunostaining of ileum paraffin section with anti-lysozyme-FITC, Wheat germ agglutinin (WGA)-Texas red and DAPI. (B) Lysozyme fluorescence intensity per crypt cell in MS (grey) compared to control (white) (n = 4 mice per group). ${ }^{*} \mathrm{p}<0,05$ compared to controls (Mann-Whitney test) (C) Number of crypts producing lysozyme on small intestine in MS (grey) compared to control (white) (n $=4$ to 5 mice per group). (D) Lysozyme enzymatic activity against peptidoglycan measured in feces of MS (grey) compared to control (white) ( $n=12$ to 13 mice per group). ${ }^{* *} \mathrm{p}<0,01$ compared to controls (Mann-Whitney test). (E) TNF $\alpha$ concentration in the ileum fragment measured by ELISA in MS (grey) compared to control (white) ( $n=6$ to 7 mice per group). * $\mathrm{p}<0,05$ compared to controls (Mann-Whitney test). 
Figure 3: Fecal microbiota population and metabolites analysis on maternally separated (MS) adult mice. (A) PLS-DA score plot of the relative quantitative abundances (Log10 No) of 20 microbial taxa in feces of MS and control mice ( $n=10$ mice per group, confidence ellipse level $=0.5$ ). VIP plot representing important features (microbial taxa) identified by PLS-DA in a descending order of importance (Relative enriched taxa appeared in red and depletion in green) in MS and control mice ( $\mathrm{n}=10$ mice per group). (B) Coefficient plots related to the O-PLS-DA model discriminating between ${ }^{1} \mathrm{H}-\mathrm{NMR}$-based spectra from fecal extracts of control (top) and MS (bottom) animals. Metabolites are color-coded according to their correlation coefficient, red indicating a very strong positive correlation. The direction of the metabolite indicates the group with which it is positively associated as labeled on the diagram. Parameters of the PLS-DA model with one predictive component and no orthogonal component: $\mathrm{R}^{2} \mathrm{Y}=0.38, \mathrm{Q}^{2} \mathrm{Y}=0.31, \mathrm{p}=0.02$ (C) The areas under the curve of the ${ }^{1} \mathrm{H}-\mathrm{NMR}$ spectra were integrated for the signals of cholic acid (singulet at $0.73 \mathrm{ppm}$ ) and lactate (doublet at $1.33 \mathrm{ppm}$ ) in MS (grey) compared to control (white) ( $\mathrm{n}=8$ mice per group). * $\mathrm{p}<0,05, * * * \mathrm{p}<0.001$ compared to controls mice (white) (Mann-Whitney test).

Figure 4: IgA in feces, ILC3 populations in small intestine and IgG response in plasma. (A) IgA concentration in feces of MS (grey) compared to control (white) (n=8 per group)* $\mathrm{p}<0,05$ compared to controls mice (Mann-Whitney test). (B) Flow cytometry analysis of ILC3 population by immunostaining with anti-ROR $\gamma \mathrm{t}$ and anti-MHC II on lamina propria cells from small intestine ( $\mathrm{n}=4$ to 6 mice per group). $* \mathrm{p}<0.05$ compared to control (MannWhitney test) (C) Plasma IgG concentrations measured by ELISA ( $\mathrm{n}=13$ to 17 mice per group) in MS (grey) compared to control (white). (D) IgG specificity against E. coli lysate assessed by ELISA after normalizing IgG concentrations in MS (grey) compared to control (white) ( $\mathrm{n}=10$ to 12 mice per group) $* * \mathrm{p}<0,01$ compared to controls (Mann-Whitney test). 
(E) IgG specificity against food lysate (hydrosoluble fraction) assessed by ELISA after normalizing IgG concentration in MS (grey) compared to control (white) (n =15 to 17 mice per group).

Figure 5 - Immune response in spleen. (A) Flow cytometry analysis of activated $\mathrm{T}$ cells $\mathrm{CD} 4{ }^{+} \mathrm{CD} 44^{\text {high }} \mathrm{CD} 62 \mathrm{~L}^{\text {low }}$ in splenocytes ( $\mathrm{n}=9$ to 14 mice per group). $* \mathrm{p}<0,05$ compared to controls mice (Mann-Whitney test) (B) Flow cytometry analysis of regulatory T cells CD4 ${ }^{+}$ $\mathrm{CD} 25^{+}$Foxp $^{+}$in splenocytes $\left(\mathrm{n}=4\right.$ to 5 mice per group). ${ }^{*} \mathrm{p}<0,05$ compared to controls mice (Mann-Whitney test) (C) IFN $\gamma$, and (D) TGF $\beta$ secretion by splenocytes in basal condition, or after anti-CD3/anti-CD28 stimulation in MS group (grey histogram) and control group (white histogram) ( $\mathrm{n}=5$ to 10 mice per group). $* * \mathrm{p}<0.01$ compared to control (Twoway ANOVA followed by Holm-Sidak's post test).

Figure 6 - MS and susceptibility to colitis in C57BL/6 IL10 ${ }^{-/-}$mice. (A) Weight, (B) colon length, (D) histological score in colon and (D) lipocalin 2 concentrations in feces of MS mice (grey) and control (white) ( $\mathrm{n}=7$ to 17 mice per group).

Figure 7 - MS and susceptibility to gastrointestinal infections. Weight and tissues colonization after oral inoculation by (A) Salmonella typhimurium $\left(10^{9} \mathrm{CFU} / \mathrm{mouse}\right)$, (B) Listeria monocytogenes Lmo-InlA ${ }^{\mathrm{m}}\left(10^{9} \mathrm{CFU} / \mathrm{ml}\right)$ or $(\mathbf{C})$ de Toxoplasma gondii $76 \mathrm{~K}$ (35 cysts) in MS mice (grey) and control (white) ( $\mathrm{n}=6$ to 12 mice per group).

Supplementary Figure 1 - (A) Typical $600 \mathrm{MHz}{ }^{1} \mathrm{H}$ NMR spectra of the fecal extracts from a control animal. (B) A spike-in experiment was performed in a representative fecal extract sample using a standard solution of cholic acid and confirmed an increase of the singulet resonating at $0.735 \mathrm{ppm}$ in the spiked sample.

Supplementary Figure 2 - Spleen weight. Spleen weight in control (white) and MS (grey) mice. $* \mathrm{p}<0.05$ compared to control (Mann-Whitney test). 


\section{References}

Avitsur, R., Levy, S., Goren, N., Grinshpahet, R., 2015. Early adversity, immunity and infectious disease. Stress. https://doi.org/10.3109/10253890.2015.1017464

Barbara, G., Cremon, C., Carini, G., Bellacosa, L., Zecchi, L., De Giorgio, R., Corinaldesi, R., Stanghellini, V., 2011. The immune system in irritable bowel syndrome. J. Neurogastroenterol. Motil. https://doi.org/10.5056/jnm.2011.17.4.349

Barreau, F., Cartier, C., Ferrier, L., Fioramonti, J., Bueno, L., 2004. Nerve growth factor mediates alterations of colonic sensitivity and mucosal barrier induced by neonatal stress in rats. Gastroenterology 127, 524-534. https://doi.org/10.1053/j.gastro.2004.05.019

Barreau, F., de Lahitte, J.D., Ferrier, L., Frexinos, J., Bueno, L., Fioramonti, J., 2006. Neonatal maternal deprivation promotes Nippostrongylus brasiliensis infection in adult rats. Brain. Behav. Immun. 20, 254-260. https://doi.org/10.1016/j.bbi.2005.07.003

Barreau, F., Ferrier, L., Fioramonti, J., Bueno, L., 2004. Neonatal maternal deprivation triggers long term alterations in colonic epithelial barrier and mucosal immunity in rats. Gut 53, 501-506. https://doi.org/10.1136/gut.2003.024174

Berg, D.J., Davidson, N., Kühn, R., Müller, W., Menon, S., Holland, G., Thompson-Snipes, L., Leach, M.W., Rennick, D., 1996. Enterocolitis and colon cancer in interleukin-10deficient mice are associated with aberrant cytokine production and CD4+Th1-like responses. J. Clin. Invest. 98, 1010-1020. https://doi.org/10.1172/JCI118861

Bergström, A., Kristensen, M.B., Bahl, M.I., Metzdorff, S.B., Fink, L.N., Frøkiær, H., Licht, T.R., 2012. Nature of bacterial colonization influences transcription of mucin genes in mice during the first week of life. BMC Res. Notes 5, 402. https://doi.org/10.1186/1756$0500-5-402$

Bergström, A., Skov, T.H., Bahl, M.I., Roager, H.M., Christensen, L.B., Ejlerskov, K.T., Mølgaard, C., Michaelsen, K.F., Licht, T.R., 2014. Establishment of intestinal microbiota during early life: A longitudinal, explorative study of a large cohort of Danish infants. Appl. Environ. Microbiol. 80, 2889-2900. https://doi.org/10.1128/AEM.0034214

Biondi, M., Zannino, L.G., 1997. Psychological stress, neuroimmunomodulation, and susceptibility to infectious diseases in animals and man: a review. Psychother. Psychosom. 66, 3-26.

Bischoff, S.C., Barbara, G., Buurman, W., Ockhuizen, T., Schulzke, J.D., Serino, M., Tilg, H., Watson, A., Wells, J.M., 2014. Intestinal permeability - a new target for disease prevention and therapy. BMC Gastroenterol. https://doi.org/10.1186/s12876-014-0189-7

Bonaz, B.L., Bernstein, C.N., 2013. Brain-gut interactions in inflammatory bowel disease. Gastroenterology 144, 36-49. https://doi.org/10.1053/j.gastro.2012.10.003

Cloarec, O., Dumas, M.E., Trygg, J., Craig, A., Barton, R.H., Lindon, J.C., Nicholson, J.K., Holmes, E., 2005. Evaluation of the orthogonal projection on latent structure model limitations caused by chemical shift variability and improved visualization of biomarker changes in1H NMR spectroscopic metabonomic studies. Anal. Chem. 77, 517-526. https://doi.org/10.1021/ac048803i 
Cohen, S., Janicki-Deverts, D., Doyle, W.J., Miller, G.E., Frank, E., Rabin, B.S., Turner, R.B., 2012. Chronic stress, glucocorticoid receptor resistance, inflammation, and disease risk. Proc. Natl. Acad. Sci. 109, 5995-5999. https://doi.org/10.1073/pnas.1118355109

Collins, S.M., 2014. A role for the gut microbiota in IBS. Nat. Rev. Gastroenterol. Hepatol. 11, 497-505. https://doi.org/10.1038/nrgastro.2014.40

Cremon, C., Pallotti, F., Bacchilega, M., Stanghellini, V., Corinaldesi, R., Barbara, G., 2008. Antiflagellin antibodies suggest infective participation in irritable bowel syndrome pathogenesis. Expert Rev. Gastroenterol. Hepatol. 2, 735-740. https://doi.org/10.1586/17474124.2.6.735

Dieterle, F., Ross, A., Schlotterbeck, G., Senn, H., 2006. Probabilistic quotient normalization as robust method to account for dilution of complex biological mixtures. Application in 1H NMR metabonomics. Anal. Chem. 78, 4281-90. https://doi.org/10.1021/ac051632c

Dowd, J.B., Palermo, T.M., Aiello, A.E., 2012. Family poverty is associated with cytomegalovirus antibody titers in U.S. children. Heal. Psychol. 31, 5-10. https://doi.org/10.1037/a0025337

Drossman, D.A., 2016. Functional gastrointestinal disorders: History, pathophysiology, clinical features, and Rome IV. Gastroenterology 150, 1262-1279e2. https://doi.org/10.1053/j.gastro.2016.02.032

Drossman, D.A., 2006. The Functional Gastrointestinal Disorders and the Rome III Process. Gastroenterology 130, 1377-1390. https://doi.org/10.1053/j.gastro.2006.03.008

Erben, U., Loddenkemper, C., Doerfel, K., Spieckermann, S., Haller, D., Heimesaat, M.M., Zeitz, M., Siegmund, B., Kühl, A.A., 2014. A guide to histomorphological evaluation of intestinal inflammation in mouse models. Int. J. Clin. Exp. Pathol. 7, 4557-4576. https://doi.org/10.1097/MOT.0000000000000150

Eriksson, L., Trygg, J., Wold, S., 2008. CV-ANOVA for significance testing of PLS and OPLS $®$ models, in: Journal of Chemometrics. pp. 594-600. https://doi.org/10.1002/cem.1187

Frehn, L., Jansen, A., Bennek, E., Mandic, A.D., Temizel, I., Tischendorf, S., Verdier, J., Tacke, F., Streetz, K., Trautwein, C., Sellge, G., 2014. Distinct patterns of IgG and IgA against food and microbial antigens in serum and feces of patients with inflammatory bowel diseases. PLoS One 9. https://doi.org/10.1371/journal.pone.0106750

Gérard, P., 2013. Metabolism of Cholesterol and Bile Acids by the Gut Microbiota. Pathogens 3, 14-24. https://doi.org/10.3390/pathogens3010014

Gitter, A.H., Bendfeldt, K., Schulzke, J.D., Fromm, M., 2000. Leaks in the epithelial barrier caused by spontaneous and TNF-alpha-induced single-cell apoptosis. FASEB J. 14, 1749-53. https://doi.org/10.1096/fj.99-0898com

Gradel, K.O., Nielsen, H.L., Schønheyder, H.C., Ejlertsen, T., Kristensen, B., Nielsen, H., 2009. Increased Short- and Long-Term Risk of Inflammatory Bowel Disease After Salmonella or Campylobacter Gastroenteritis. Gastroenterology 137, 495-501. https://doi.org/10.1053/j.gastro.2009.04.001

Halpin, S.J., Ford, A.C., 2012. Prevalence of symptoms meeting criteria for irritable bowel 
syndrome in inflammatory bowel disease: systematic review and meta-analysis. Am. J. Gastroenterol. 107, 1474-82. https://doi.org/10.1038/ajg.2012.260

Hepworth, M.R., Monticelli, L.A., Fung, T.C., Ziegler, C.G.K., Grunberg, S., Sinha, R., Mantegazza, A.R., Ma, H.-L., Crawford, A., Angelosanto, J.M., Wherry, E.J., Koni, P.A., Bushman, F.D., Elson, C.O., Eberl, G., Artis, D., Sonnenberg, G.F., 2013. Innate lymphoid cells regulate CD4+ T-cell responses to intestinal commensal bacteria. Nature 498, 113-117. https://doi.org/10.1038/nature12240

Hislop, I.G., 1979. Childhood deprivation: An antecedent of the irritable bowel syndrome. Med. J. Aust. 1, 372-374.

Holmen, N., Isaksson, S., Simren, M., Sjovall, H., Ohman, 1, 2007. CD4+CD25+ regulatory T cells in irritable bowel syndrome patients. Neurogastroenterol. Motil. 19, 119-125. https://doi.org/doi:10.1111/j.1365-2982.2006.00878.x

Ironson, G., O’Cleirigh, C., Fletcher, M.A., Laurenceau, J.P., Balbin, E., Klimas, N., Schneiderman, N., Solomon, G., 2005. Psychosocial Factors Predict CD4 and Viral Load Change in Men and Women With Human Immunodeficiency Virus in the Era of Highly Active Antiretroviral Treatment. Psychosom. Med. 67, 1013-1021. https://doi.org/10.1097/01.psy.0000188569.58998.c8

Kupferschmidt, O., Krüger, D., Held, T.K., Ellerbrok, H., Siegert, W., Janitschke, K., 2001. Quantitative detection of Toxoplasma gondii DNA in human body fluids by TaqMan polymerase chain reaction. Clin. Microbiol. Infect. 7, 120-124. https://doi.org/clm224 [pii]

Landers, C.J., Cohavy, O., Misra, R., Yang, H., Lin, Y.C., Braun, J., Targan, S.R., 2002. Selected loss of tolerance evidenced by Crohn's disease-associated immune responses to auto- and microbial antigens. Gastroenterology 123, 689-699. https://doi.org/10.1053/gast.2002.35379

Lennon, E.M., Maharshak, N., Elloumi, H., Borst, L., Plevy, S.E., Moeser, A.J., 2013. Early life stress triggers persistent colonic barrier dysfunction and exacerbates colitis in adult IL-10-/- Mice. Inflamm. Bowel Dis. 19, 712-719. https://doi.org/10.1097/MIB.0b013e3182802a4e

Lodes, M.J., Cong, Y., Elson, C.O., Mohamath, R., Landers, C.J., Targan, S.R., Fort, M., Hershberg, R.M., 2004. Bacterial flagellin is a dominant antigen in Crohn disease. J. Clin. Invest. 113, 1296-1306. https://doi.org/10.1172/JCI200420295

Loizzo, A., Loizzo, S., Lopez, L., D’Amore, A., Renzi, P., Spampinato, S., Di Carlo, S., Bacosi, A., Zuccaro, P., Pacifici, R., 2002. Naloxone prevents cell-mediated immune alterations in adult mice following repeated mild stress in the neonatal period. Br. J. Pharmacol. 135, 1219-1226. https://doi.org/10.1038/sj.bjp.0704577

Lovell, R.M., Ford, A.C., 2012. Global Prevalence of and Risk Factors for Irritable Bowel Syndrome: A Meta-analysis. Clin. Gastroenterol. Hepatol. https://doi.org/10.1016/j.cgh.2012.02.029

Lowman, B.C., Drossman, D.A., Cramer, E.M., McKee, D.C., 1987. Recollection of childhood events in adults with irritable bowel syndrome, Journal of Clinical Gastroenterology. 
Lu, D., Sundstrom, K., Sparen, P., Fall, K., Sjolander, A., Dillner, J., Helm, N.Y., Adami, H.O., Valdimarsdottir, U., Fang, F., 2016. Bereavement Is Associated with an Increased Risk of HPV Infection and Cervical Cancer: An Epidemiological Study in Sweden. Cancer Res. 76, 643-651. https://doi.org/10.1158/0008-5472.CAN-15-1788

Marco, E.M., Llorente, R., López-Gallardo, M., Mela, V., Llorente-Berzal, Á., Prada, C., Viveros, M.-P., 2015. The maternal deprivation animal model revisited. Neurosci. Biobehav. Rev. 51, 151-63. https://doi.org/10.1016/j.neubiorev.2015.01.015

Maunder, R., 2000. Mediators of stress effects in inflammatory bowel disease: Not the usual suspects. J. Psychosom. Res. 48, 569-577. https://doi.org/10.1016/S00223999(00)00098-2

Mayer, E.A., Naliboff, B.D., Chang, L., Coutinho, S. V, 2001. Stress and irritable bowel syndrome. Am. J. ... 280, G519-24.

Melinder, C., Hiyoshi, A., Kasiga, T., Halfvarson, J., Fall, K., Montgomery, S., 2017. Resilience to stress and risk of gastrointestinal infections. Eur. J. Public Health. https://doi.org/10.1093/eurpub/ckx179

O’Mahony, C., Scully, P., O’Mahony, D., Murphy, S., O’Brien, F., Lyons, A., Sherlock, G., MacSharry, J., Kiely, B., Shanahan, F., O’Mahony, L., 2008. Commensal-induced regulatory $\mathrm{T}$ cells mediate protection against pathogen-stimulated NF- $\kappa \mathrm{B}$ activation. PLoS Pathog. 4. https://doi.org/10.1371/journal.ppat.1000112

O’Mahony, S.M., Hyland, N.P., Dinan, T.G., Cryan, J.F., 2011. Maternal separation as a model of brain-gut axis dysfunction. Psychopharmacology (Berl). https://doi.org/10.1007/s00213-010-2010-9

O’Mahony, S.M., Marchesi, J.R., Scully, P., Codling, C., Ceolho, A.M., Quigley, E.M.M., Cryan, J.F., Dinan, T.G., 2009. Early Life Stress Alters Behavior, Immunity, and Microbiota in Rats: Implications for Irritable Bowel Syndrome and Psychiatric Illnesses. Biol. Psychiatry 65, 263-267. https://doi.org/10.1016/j.biopsych.2008.06.026

Ohman, L., Isaksson, S., Lindmark, A.-C., Posserud, I., Stotzer, P.-O., Strid, H., Sjövall, H., Simrén, M., 2009. T-cell activation in patients with irritable bowel syndrome. Am. J. Gastroenterol. 104, 1205-12. https://doi.org/10.1038/ajg.2009.116

Peleman, C., Camilleri, M., Busciglio, I., Burton, D., Donato, L., Zinsmeister, A.R., 2017. Colonic Transit and Bile Acid Synthesis or Excretion in Patients With Irritable Bowel Syndrome-Diarrhea Without Bile Acid Malabsorption. Clin. Gastroenterol. Hepatol. 15, 720-727.e1. https://doi.org/10.1016/j.cgh.2016.11.012

Piche, T., Barbara, G., Aubert, P., Des Varannes, S.B., Dainese, R., Nano, J.L., Cremon, C., Stanghellini, V., De Giorgio, R., Galmiche, J.P., Neunlist, M., 2009. Impaired Intestinal barrier integrity in the colon of patients with irritable bowel syndrome: Involvement of soluble mediators. Gut 58, 196-201. https://doi.org/10.1136/gut.2007.140806

Porter, C.K., Cash, B.D., Pimentel, M., Akinseye, A., Riddle, M.S., 2012. Risk of inflammatory bowel disease following a diagnosis of irritable bowel syndrome. BMC Gastroenterol. 12. https://doi.org/10.1186/1471-230X-12-55

Qiu, B.S., Vallance, B.A., Blennerhassett, P. a, Collins, S.M., 1999. The role of CD4+ lymphocytes in the susceptibility of mice to stress-induced reactivation of experimental 
colitis. Nat. Med. 5, 1178-1182. https://doi.org/10.1038/13503

Rajilić-Stojanović, M., Biagi, E., Heilig, H.G.H.J., Kajander, K., Kekkonen, R.A., Tims, S., De Vos, W.M., 2011. Global and deep molecular analysis of microbiota signatures in fecal samples from patients with irritable bowel syndrome. Gastroenterology 141, 1792 1801. https://doi.org/10.1053/j.gastro.2011.07.043

Renz, H., Brandtzaeg, P., Hornef, M., 2012. The impact of perinatal immune development on mucosal homeostasis and chronic inflammation. Nat. Rev. Immunol. 12, 9-23. https://doi.org/10.1038/nri3112

Riba, A., Olier, M., Lacroix-Lamandé, S., Lencina, C., Bacquié, V., Harkat, C., Gillet, M., Baron, M., Sommer, C., Mallet, V., Salvador-Cartier, C., Laurent, F., Théodorou, V., Ménard, S., 2017. Paneth Cell Defects Induce Microbiota Dysbiosis in Mice and Promote Visceral Hypersensitivity. Gastroenterology 153, 1594-1606.e2. https://doi.org/10.1053/j.gastro.2017.08.044

Schoepfer, A.M., Schaffer, T., Seibold-Schmid, B., Müller, S., Seibold, F., 2008. Antibodies to flagellin indicate reactivity to bacterial antigens in IBS patients. Neurogastroenterol. Motil. 20, 1110-1118. https://doi.org/10.1111/j.1365-2982.2008.01166.x

Schultz, M., Lai, C.C. hua., Lindstroem, A.L. is., Stein, K., Donaldson, G., ThompsonFawcett, M., Butt, A.G., 2015. Aggravation of Established Colitis in Specific Pathogenfree IL-10 Knockout Mice by Restraint Stress Is Not Mediated by Increased Colonic Permeability. J. Crohns. Colitis 9, 754-762. https://doi.org/10.1093/ecco-jcc/jjv098

Schultz, M., Veltkamp, C., Dieleman, L.A., Grenther, W.B., Wyrick, P.B., Tonkonogy, S.L., Balfour Sartor, R., 2002. Lactobacillus plantarum 299V in the treatment and prevention of spontaneous colitis in interleukin-10-deficient mice. Inflamm. Bowel Dis. 8, 71-80. https://doi.org/10.1097/00054725-200203000-00001

Sellon, R.K., Tonkonogy, S., Schultz, M., Dieleman, L.A., Grenther, W., Balish, E., Rennick, D.M., Sartor, R.B., 1998. Resident enteric bacteria are necessary for development of spontaneous colitis and immune system activation in interleukin-10-deficient mice. Infect. Immun. 66, 5224-5231.

Shiga, H., Miyazawa, T., Kinouchi, Y., Takahashi, S.S., Tominaga, G., Takahashi, H., Takagi, S., Obana, N., Kikuchi, T., Oomori, S., Nomura, E., Shiraki, M., Sato, Y., Umemura, K., Yokoyama, H., Endo, K., Kakuta, Y., Aizawa, H., Matsuura, M., Kimura, T., Kuroha, M., Shimosegawa, T., Takahashi, S.S., Umemura, K., Yokoyama, H., Endo, K., Kakuta, Y., Aizawa, H., Matsuura, M., Kimura, T., Kuroha, M., Shimosegawa, T., 2013. Life-event stress induced by the Great East Japan Earthquake was associated with relapse in ulcerative colitis but not Crohn's disease: a retrospective cohort study. BMJ Open 3, 1-8. https://doi.org/10.1136/bmjopen-2012-002294

Shin, A., Camilleri, M., Vijayvargiya, P., Busciglio, I., Burton, D., Ryks, M., Rhoten, D., Lueke, A., Saenger, A., Girtman, A., Zinsmeister, A.R., 2013. Bowel functions, fecal unconjugated primary and secondary bile acids, and colonic transit in patients with irritable bowel syndrome. Clin. Gastroenterol. Hepatol. 11, 1270-1275. https://doi.org/10.1016/j.cgh.2013.04.020

Shirtcliff, E.A., Coe, C.L., Pollak, S.D., 2009. Early childhood stress is associated with elevated antibody levels to herpes simplex virus type 1. Proc. Natl. Acad. Sci. U. S. A. 
106, 2963-2967. https://doi.org/10.1073/pnas.0806660106

Slopen, N., McLaughlin, K.A., Dunn, E.C., Koenen, K.C., 2013. Childhood adversity and cell-mediated immunity in young adulthood: Does type and timing matter? Brain. Behav. Immun. 28, 63-71. https://doi.org/10.1016/j.bbi.2012.10.018

Sonnenberg, G.F., Monticelli, L.A., Alenghat, T., Fung, T.C., Hutnick, N.A., Kunisawa, J., Shibata, N., Grunberg, S., Sinha, R., Zahm, A.M., Tardif, M.R., Sathaliyawala, T., Kubota, M., Farber, D.L., Collman, R.G., Shaked, A., Fouser, L.A., Weiner, D.B., Tessier, P.A., Friedman, J.R., Kiyono, H., Bushman, F.D., Chang, K.M., Artis, D., 2012. Innate lymphoid cells promote anatomical containment of lymphoid-resident commensal bacteria. Science (80-. ). 336, 1321-1325. https://doi.org/10.1126/science.1222551

Tenenhaus, M., 1998. La regression PLS:theorie et pratique, Technip Ed. ed. Paris.

Ternhag, A., Törner, A., Svensson, A., Ekdahl, K., Giesecke, J., 2008. Short- and long-term effects of bacterial gastrointestinal infections. Emerg. Infect. Dis. 14, 143-8. https://doi.org/10.3201/eid1401.070524

Trygg, J., Wold, S., 2002. Orthogonal projections to latent structures (O-PLS). J. Chemom. 16, 119-128. https://doi.org/10.1002/cem.695

Van Hauwermeiren, F., Vandenbroucke, R.E., Grine, L., Lodens, S., Van Wonterghem, E., De Rycke, R., De Geest, N., Hassan, B., Libert, C., 2014. TNFR1-induced lethal inflammation is mediated by goblet and Paneth cell dysfunction. Mucosal Immunol. 113. https://doi.org/10.1038/mi.2014.112

Varghese, A.K., Verdú, E.F., Bercik, P., Khan, W.I., Blennerhassett, P.A., Szechtman, H., Collins, S.M., 2006. Antidepressants Attenuate Increased Susceptibility to Colitis in a Murine Model of Depression. Gastroenterology 130, 1743-1753. https://doi.org/10.1053/j.gastro.2006.02.007

Veselkov, K.A., Lindon, J.C., Ebbels, T.M.D., Crockford, D., Volynkin, V. V., Holmes, E., Davies, D.B., Nicholson, J.K., 2009. Recursive Segment-Wise Peak Alignment of Biological ${ }^{1}$ H NMR Spectra for Improved Metabolic Biomarker Recovery. Anal. Chem. 81, 56-66. https://doi.org/10.1021/ac8011544

Videlock, E.J., Adeyemo, M., Licudine, A., Hirano, M., Ohning, G., Mayer, M., Mayer, E.A., Chang, L., 2009. Childhood Trauma Is Associated With Hypothalamic-Pituitary-Adrenal Axis Responsiveness in Irritable Bowel Syndrome. Gastroenterology 137, 1954-1962. https://doi.org/10.1053/j.gastro.2009.08.058

Wehkamp, J., 2005. Reduced Paneth cell a-defensins in ileal Crohn's disease. Proc. Natl. Acad. Sci. 102, 18129-18134. https://doi.org/10.1073/pnas.0505256102

Wollert, T., Pasche, B., Rochon, M., Deppenmeier, S., van den Heuvel, J., Gruber, A.D., Heinz, D.W., Lengeling, A., Schubert, W.-D., 2007. Extending the host range of Listeria monocytogenes by rational protein design. Cell 129, 891-902. https://doi.org/10.1016/j.cell.2007.03.049

Wood, J.D., 2011. Visceral pain: spinal afferents, enteric mast cells, enteric nervous system and stress. Curr. Pharm. Des. 17, 1573-5.

Wyatt, J., Vogelsang, H., Hübl, W., Waldhöer, T., Lochs, H., 1993. Intestinal permeability 
and the prediction of relapse in Crohn's disease. Lancet 341, 1437-1439.

https://doi.org/10.1016/0140-6736(93)90882-H

Yi, L., Zhang, H., Sun, H., Zhou, L., Chen, Y., Xuan, L., Jiang, Y., Xu, S., 2017. Maternal Separation Induced Visceral Hypersensitivity from Childhood to Adulthood. J. Neurogastroenterol. Motil. 23, 306-315. https://doi.org/10.5056/jnm16089

Yvon, S., Olier, M., Leveque, M., Jard, G., Tormo, H., Haimoud-Lekhal, D.A., Peter, M., Eutamène, H., 2016. Donkey milk consumption exerts anti-inflammatory properties by normalizing antimicrobial peptides levels in Paneth's cells in a model of ileitis in mice. Eur. J. Nutr. https://doi.org/10.1007/s00394-016-1304-z

Zhao, X.-J., Hao, F., Huang, C., Rantalainen, M., Lei, H., Tang, H., Wang, Y., 2012. Systems responses of rats to mequindox revealed by metabolic and transcriptomic profiling. J. Proteome Res. 11, 4712-21. https://doi.org/10.1021/pr300533a

Zhou, X.-Y., 2016. Visceral hypersensitive rats share common dysbiosis features with irritable bowel syndrome patients. World J. Gastroenterol. 22, 5211. https://doi.org/10.3748/wjg.v22.i22.5211 


\section{Highlights:}

- Early life stress in mice is a unique model gathering IBS features i.e. visceral hypersensitivity, intestinal hyper-permeability, low grade inflammation, microbiota dysbiosis and bile acid malabsorption.

- Early life stress do not precipitate nor exacerbate colitis in mouse models genetically predisposed to IBD

- Early life stress do not increase susceptibility to gastrointestinal pathogen infections.

- Early life stress induces long lasting consequences on intestinal barrier that do not impair the ability of intestinal barrier to prevent enteric infections or contain colitis. This result is consistent with epidemiological studies. 


\section{Figure 1}

A

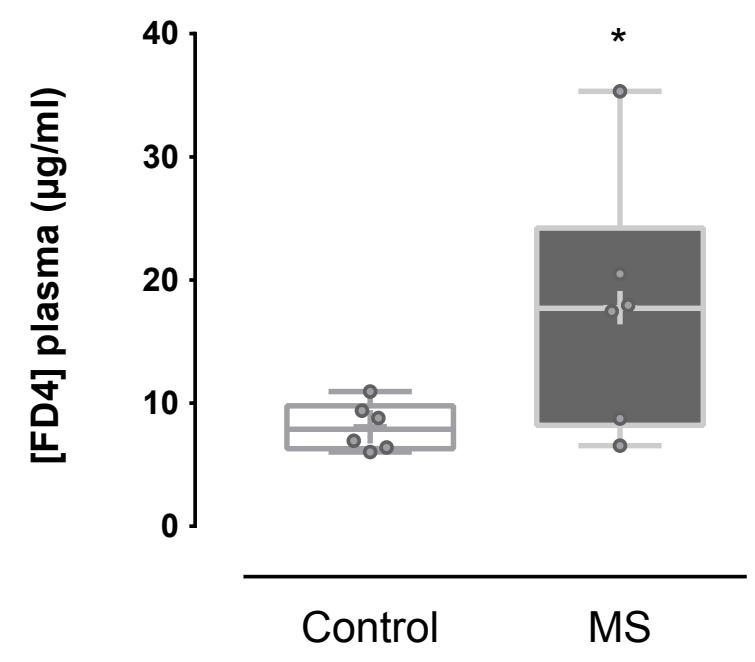

B
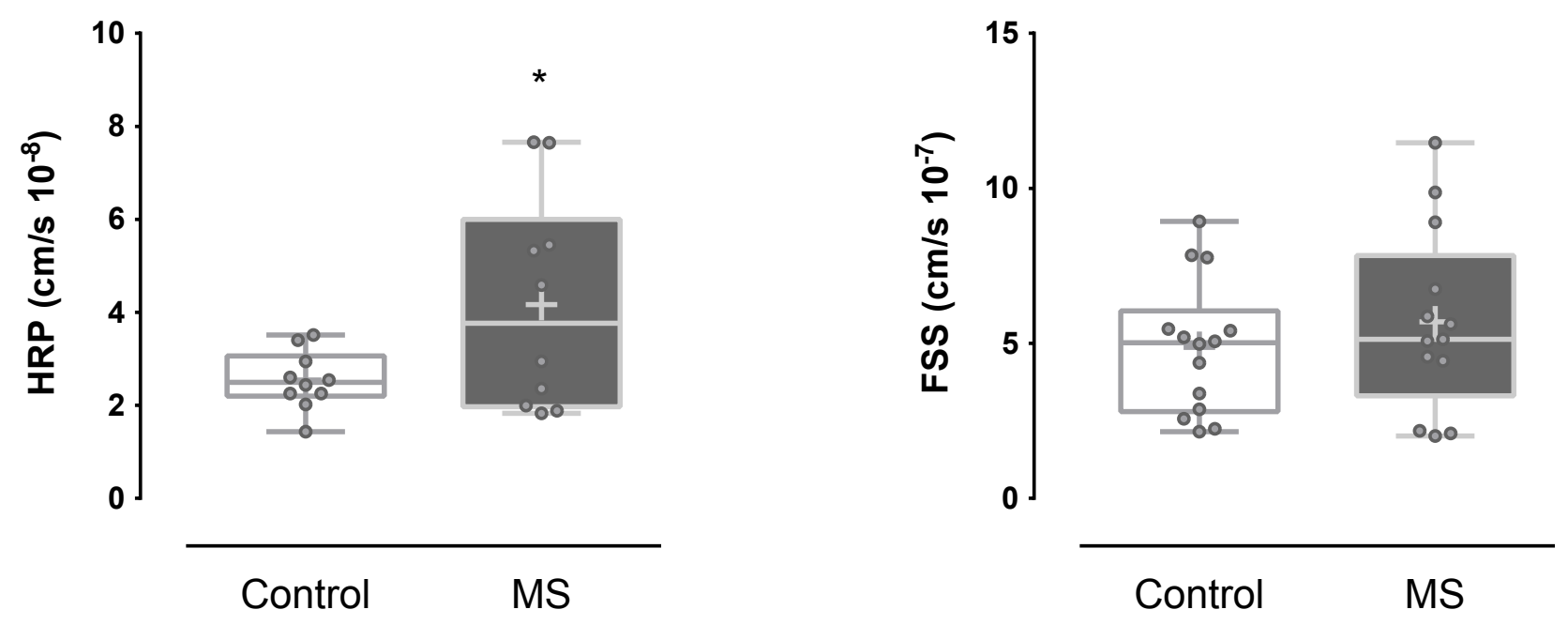

C

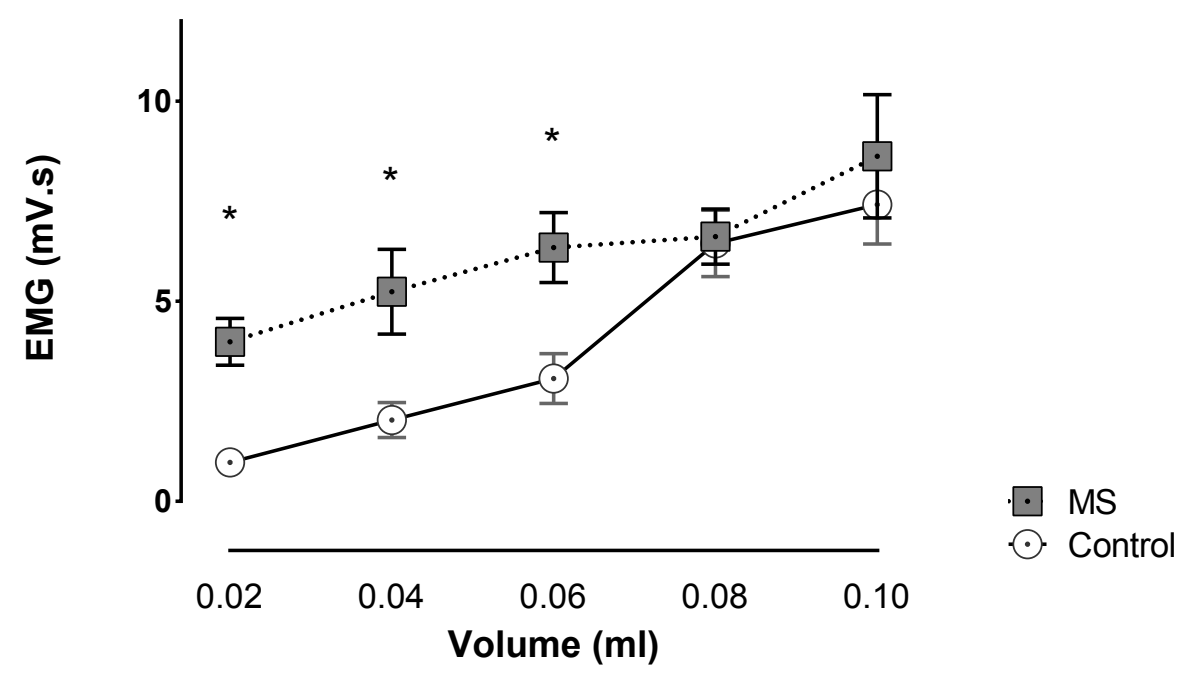




\section{Figure 2}

A
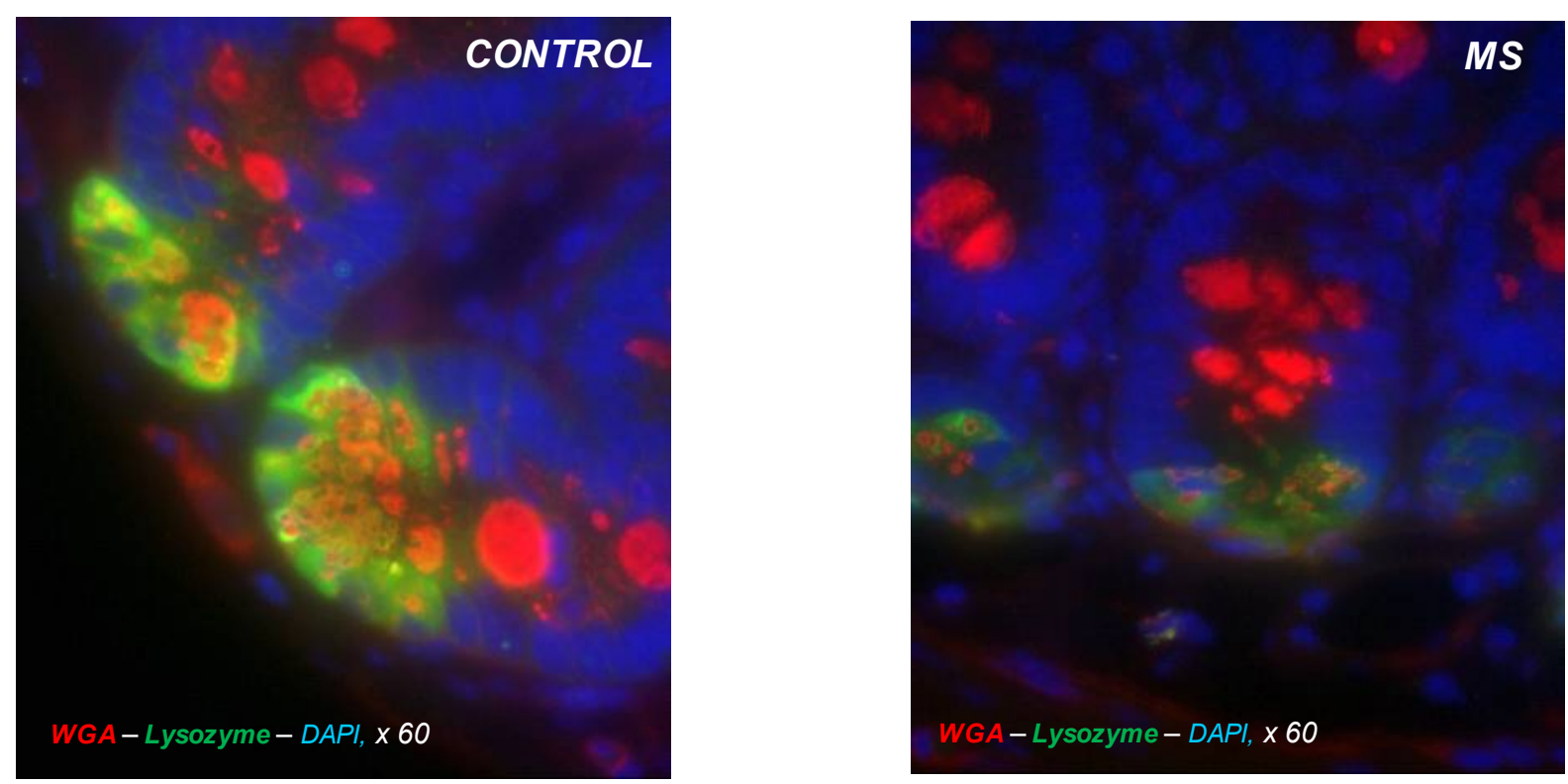

B
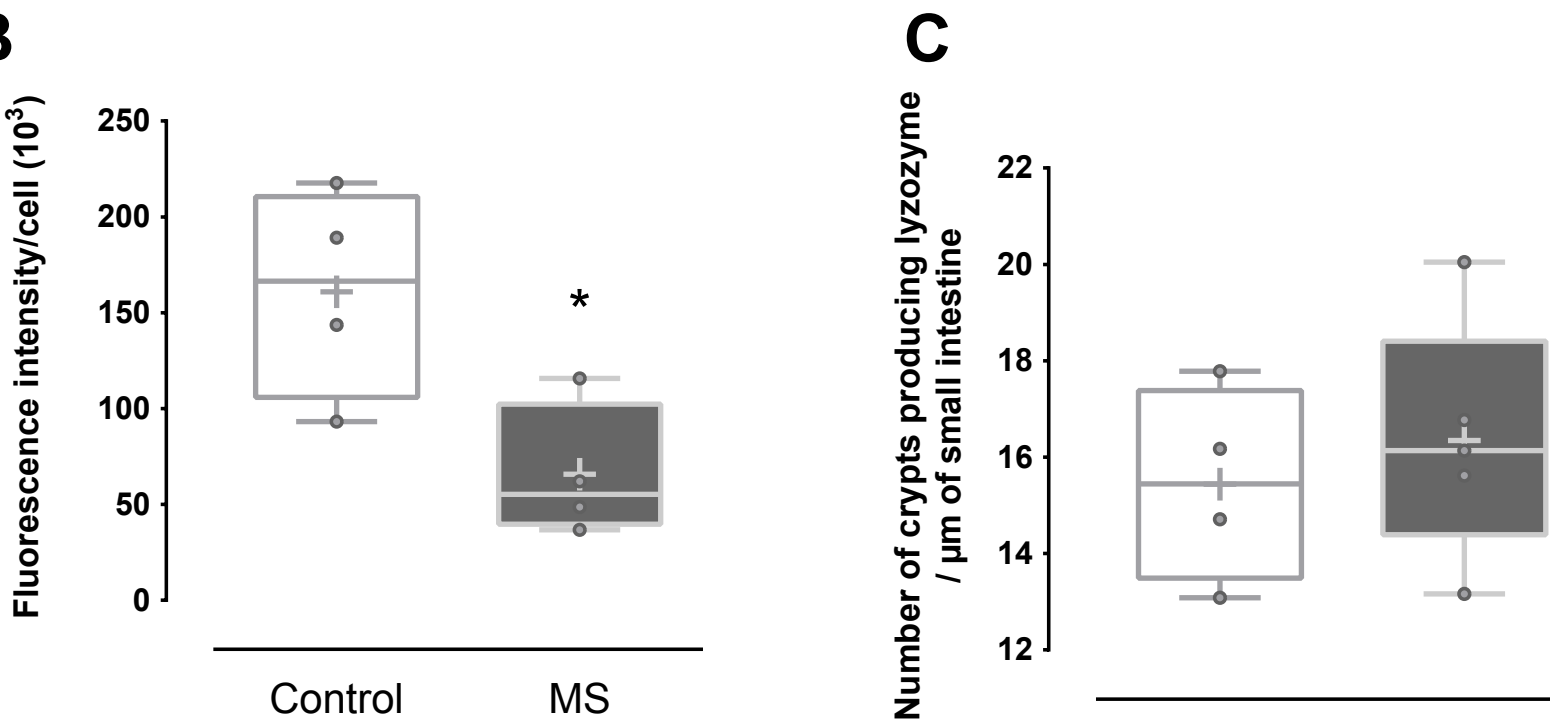

Control MS

Control

MS

D
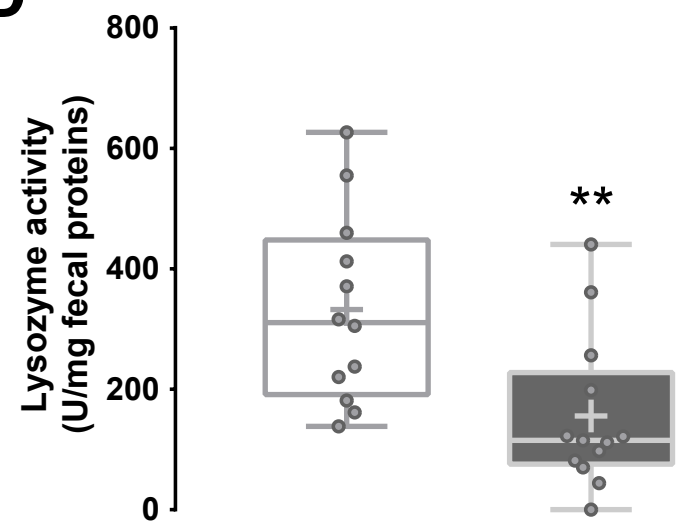

E
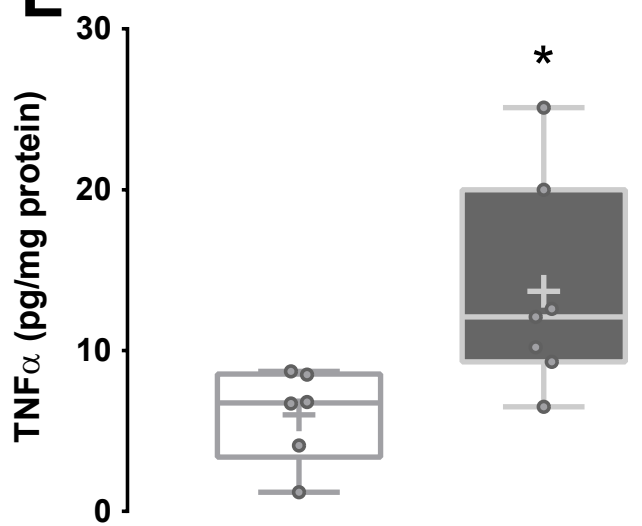

Control

MS 


\section{Figure 3}

\section{A}

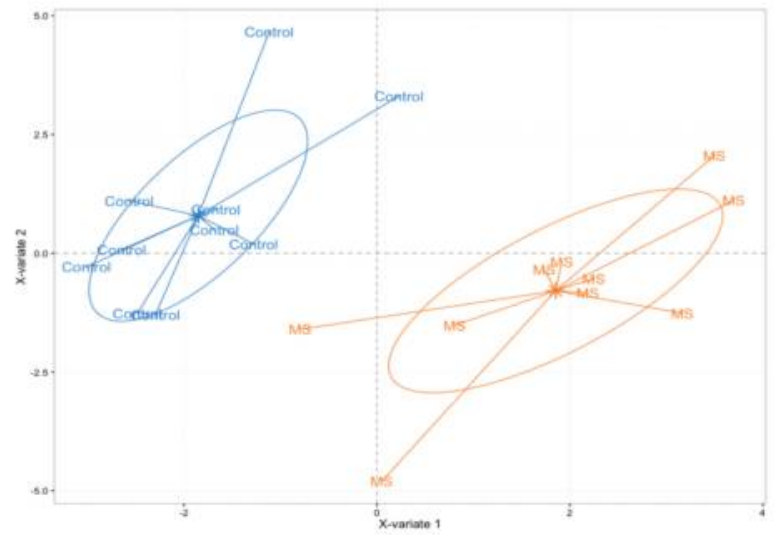

Bifidobacterium spp.

E. hallii

Roseburia spp.

C. butyricum

Desulfovibrio spp.

A. muciniphila

Prevotella spp.

M. smithii

$B$. fragilis

Enterococcus spp.

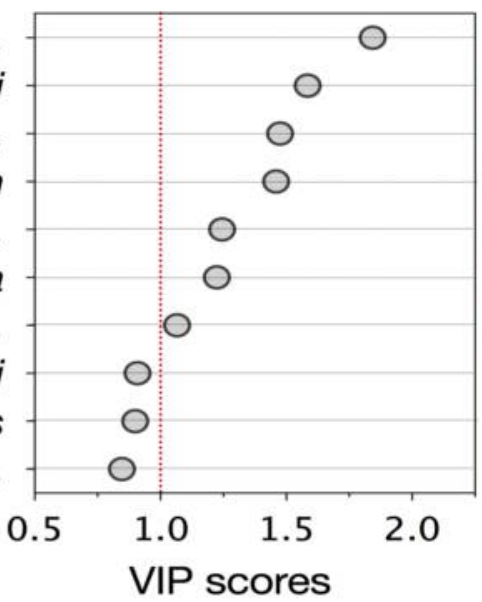

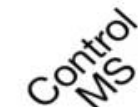

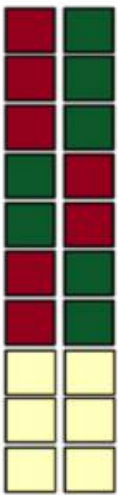

High

Low

B

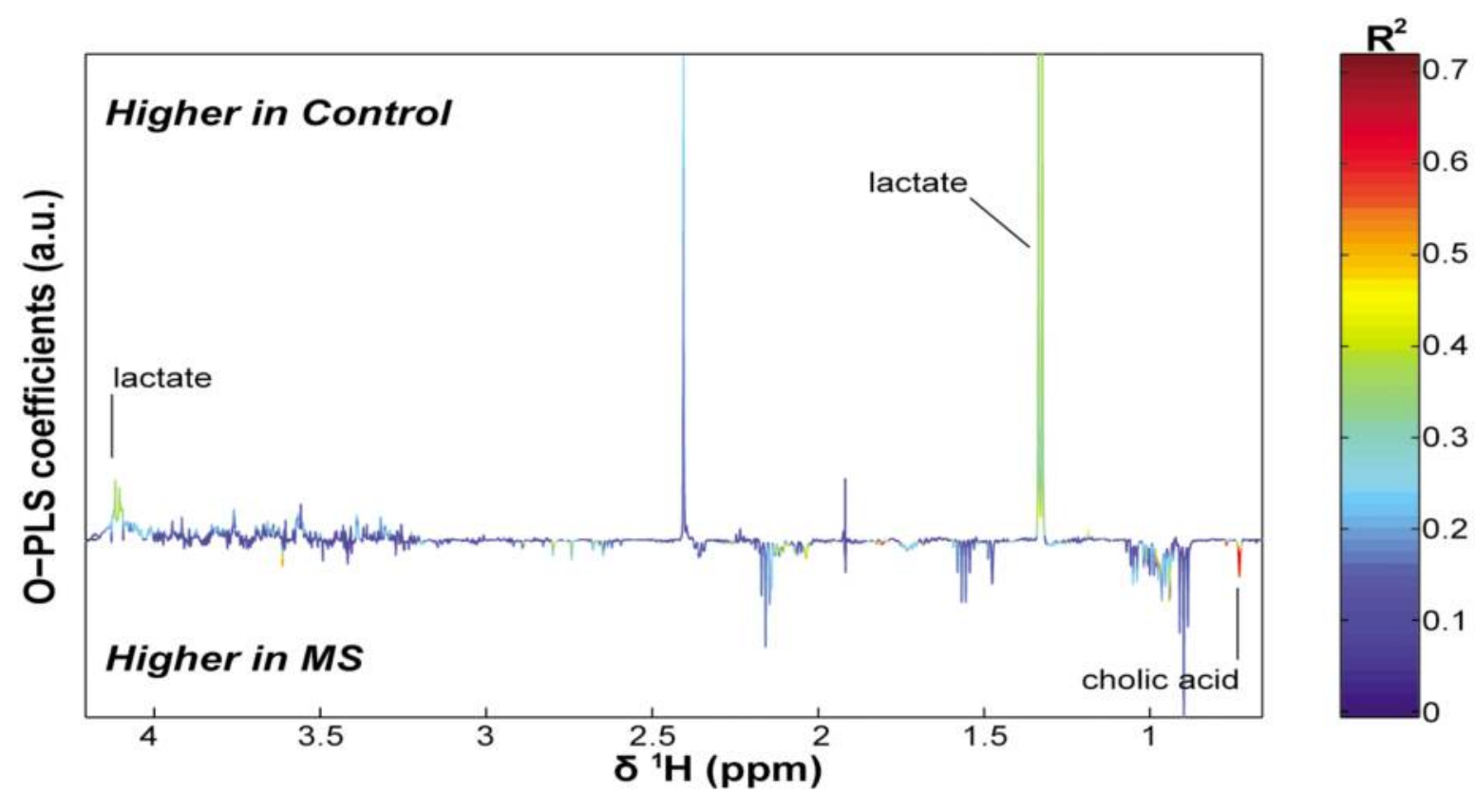

C
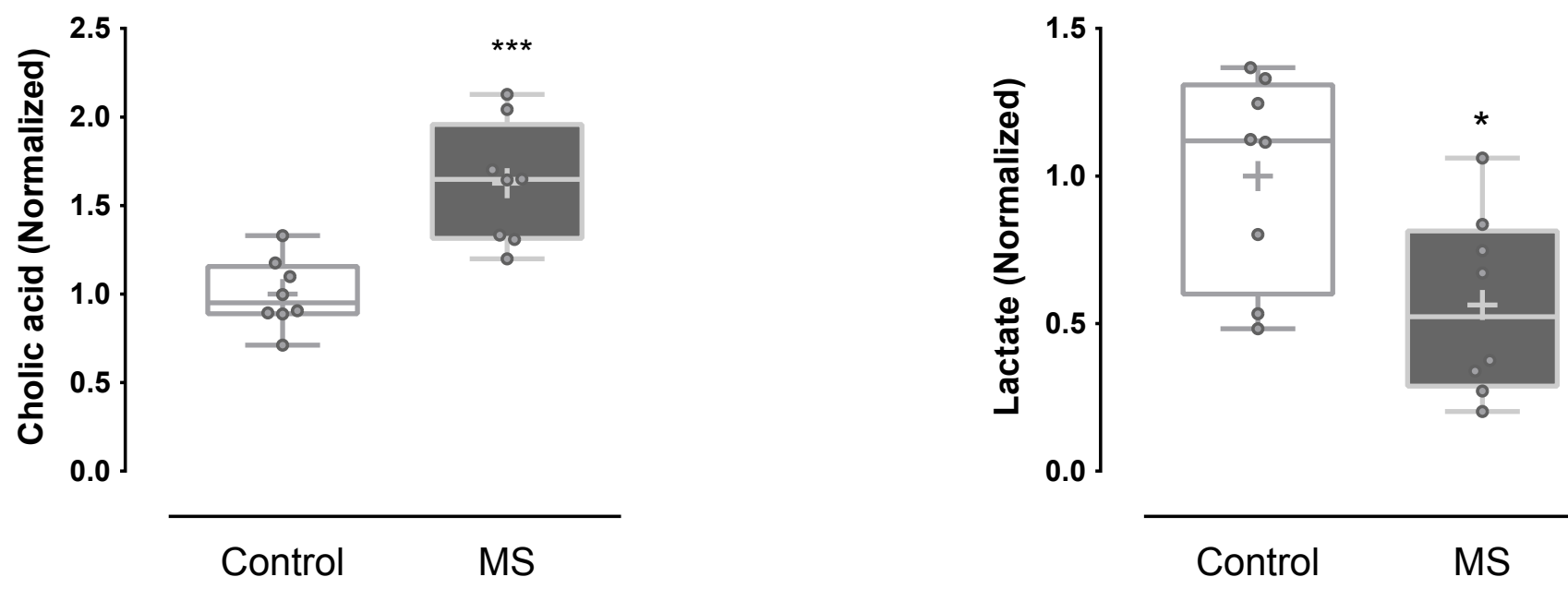

Control

MS 


\section{Figure 4}

A

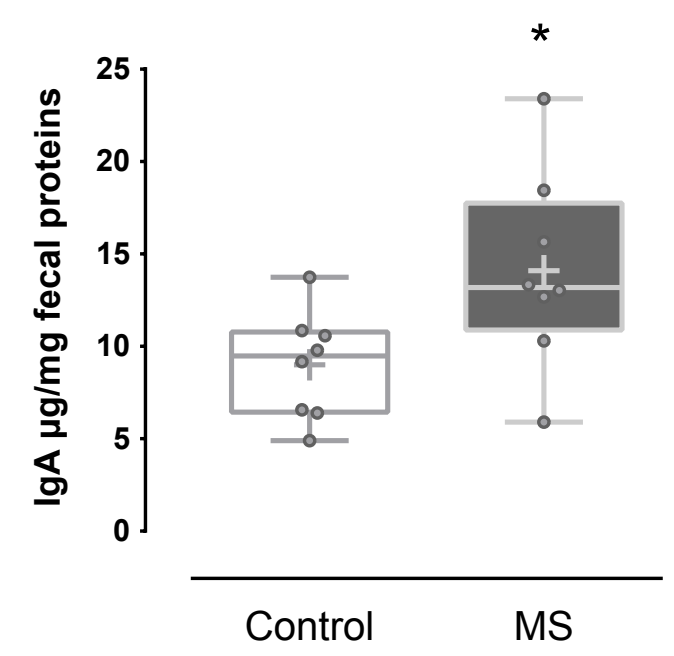

C

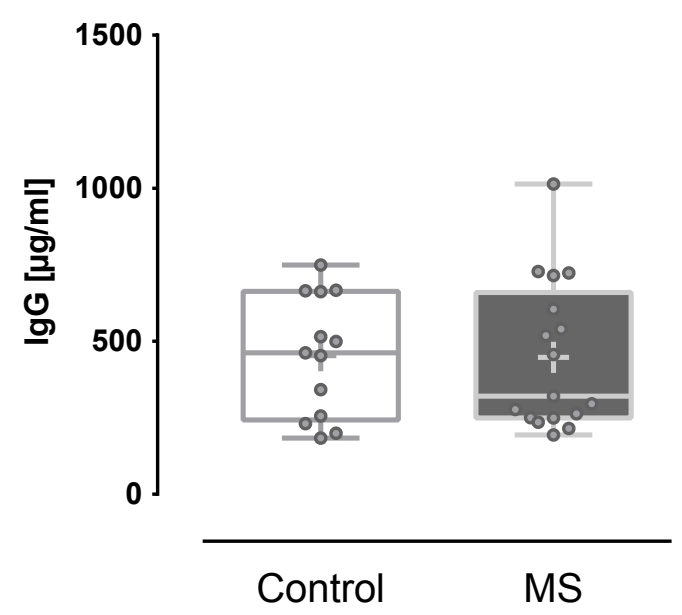

B

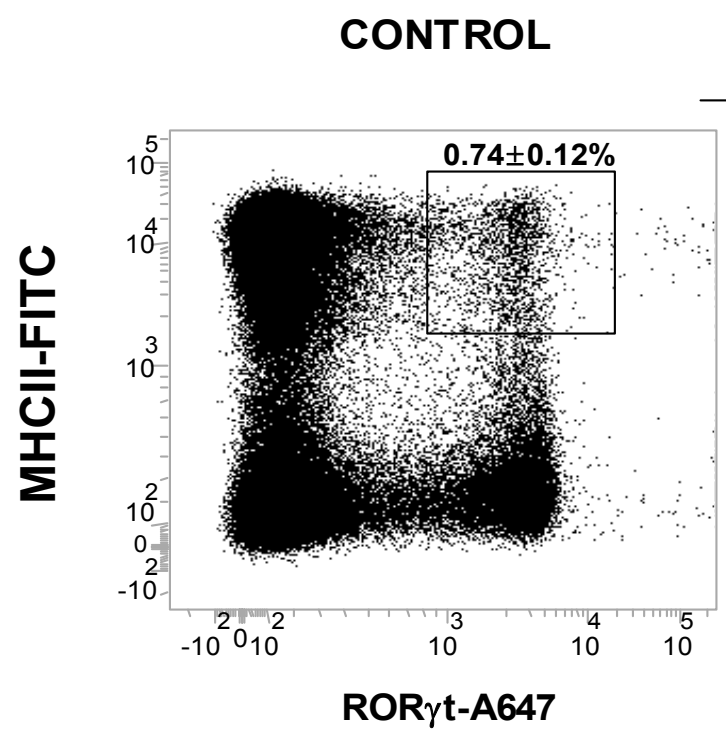

D

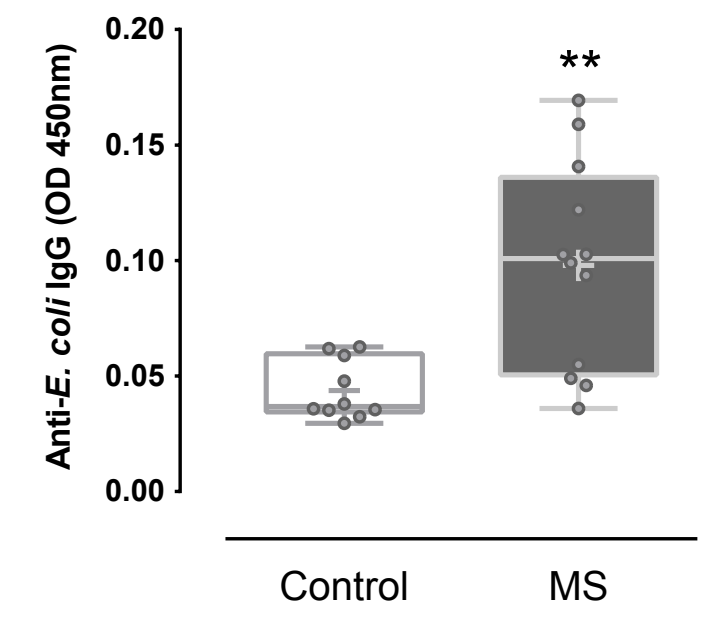

MS

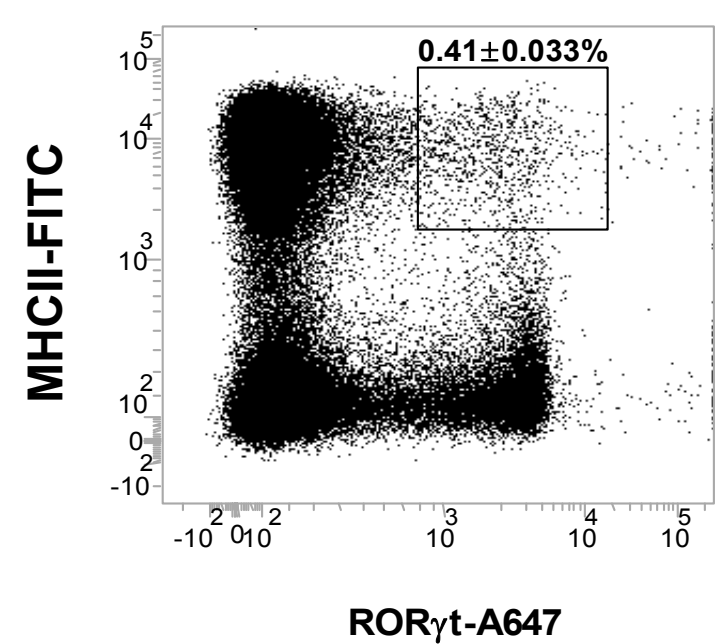

E

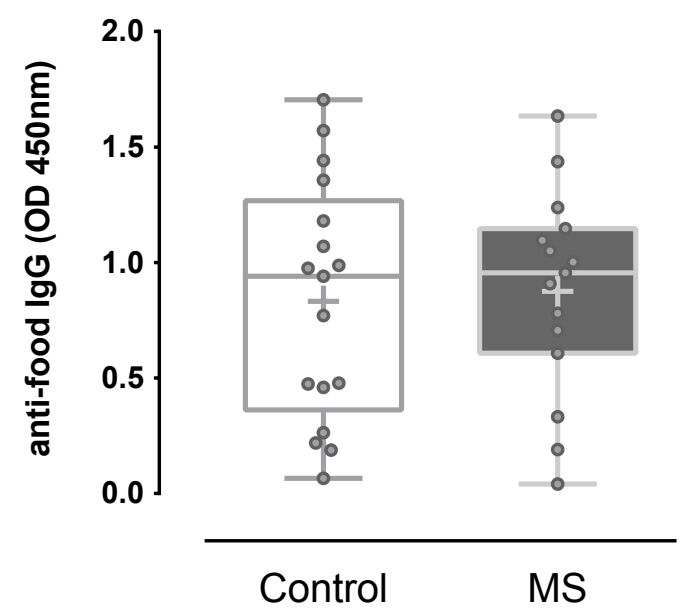




\section{Figure 5}

A

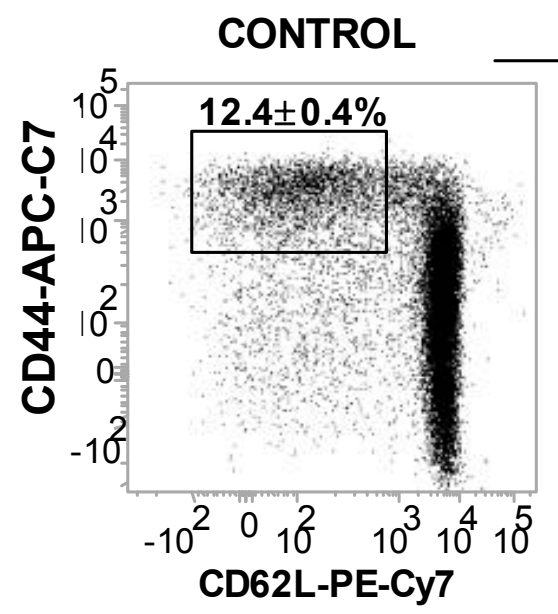

C

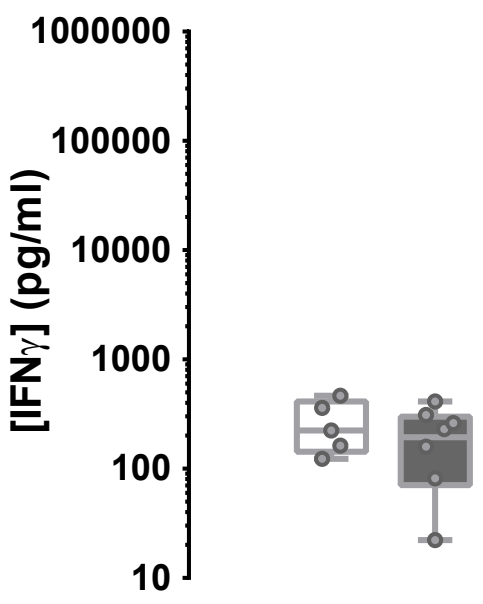

MS

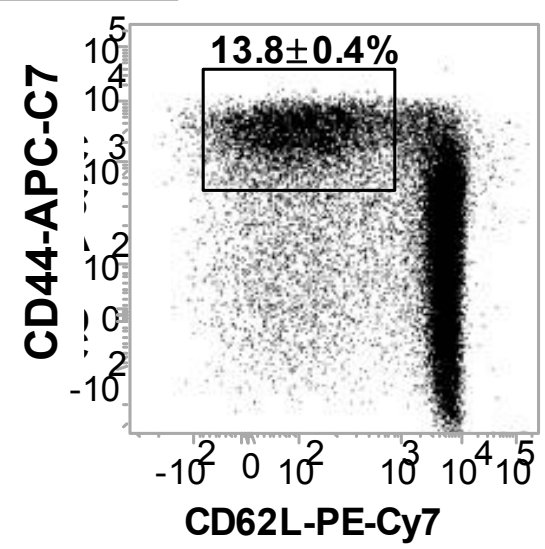

$\square$ Control

$\square \mathrm{MS}$

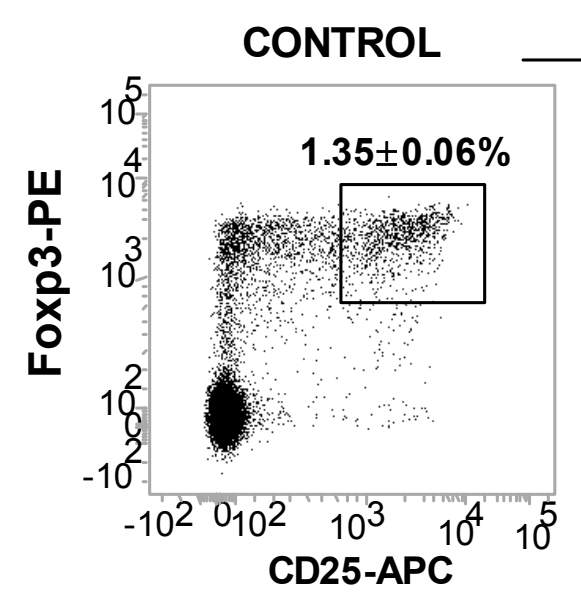

D

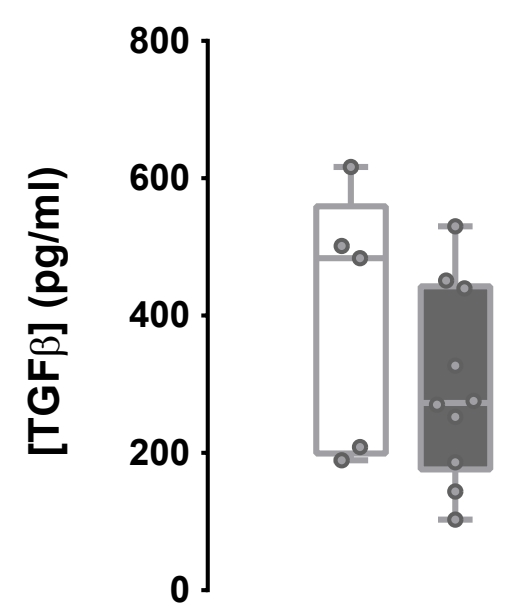

*

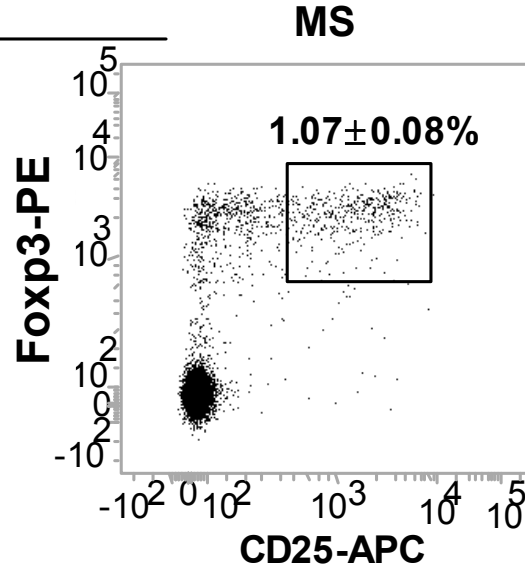

$\square$ Control $\square$ MS 


\section{Figure 6}

A

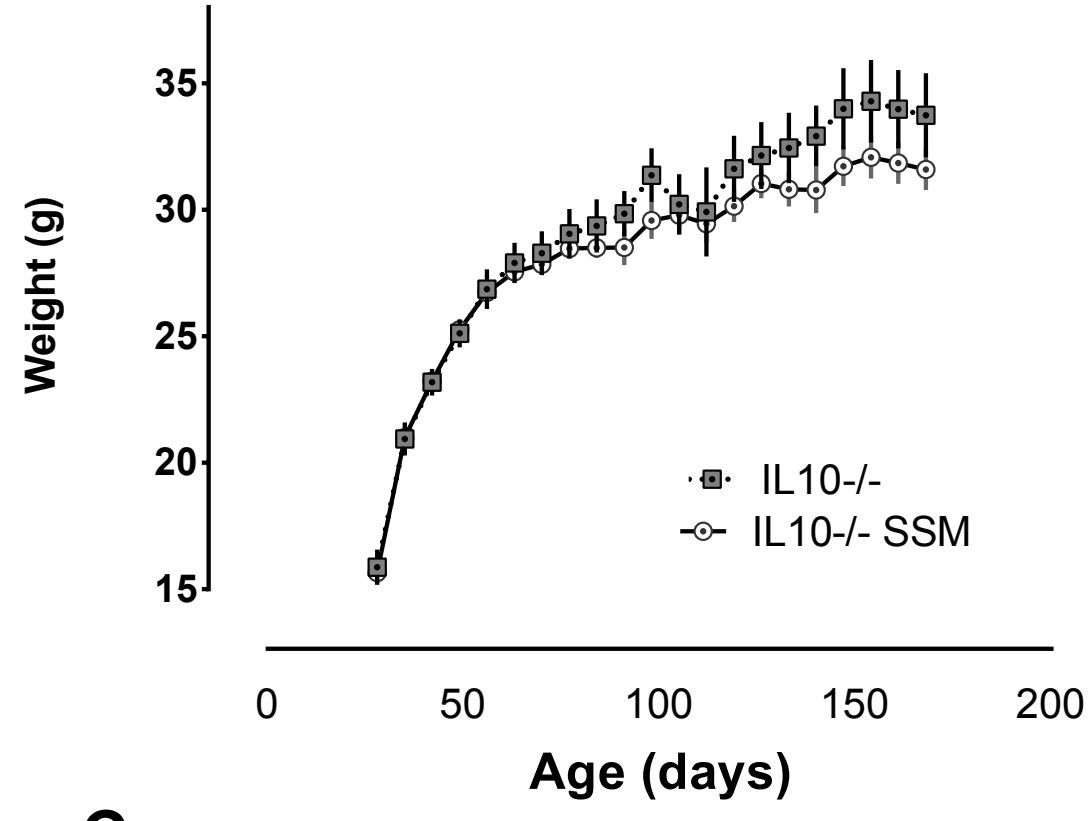

C

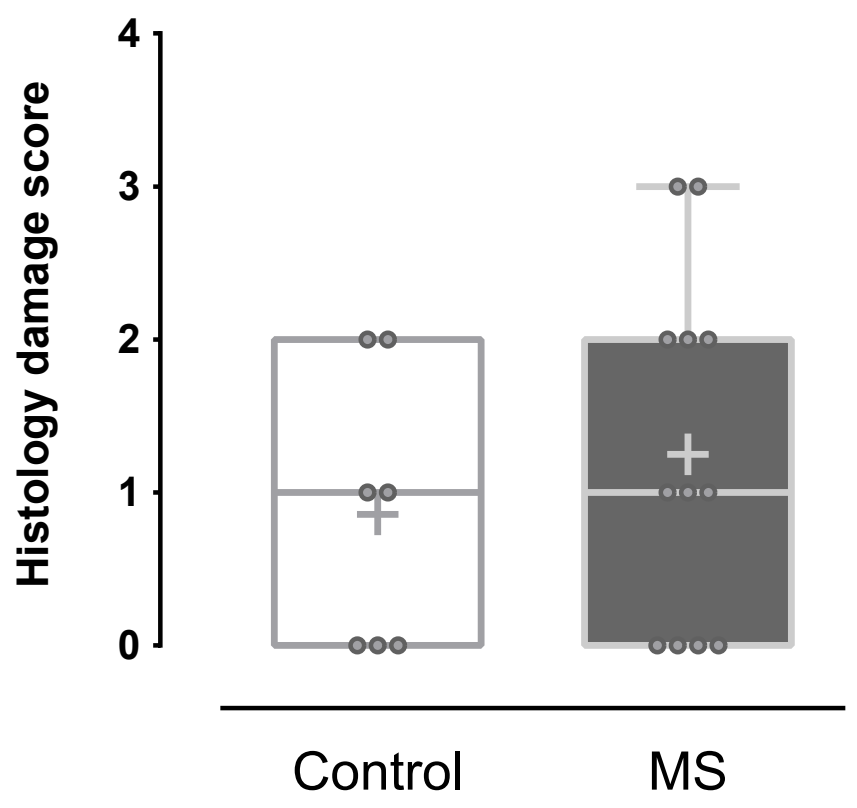

B

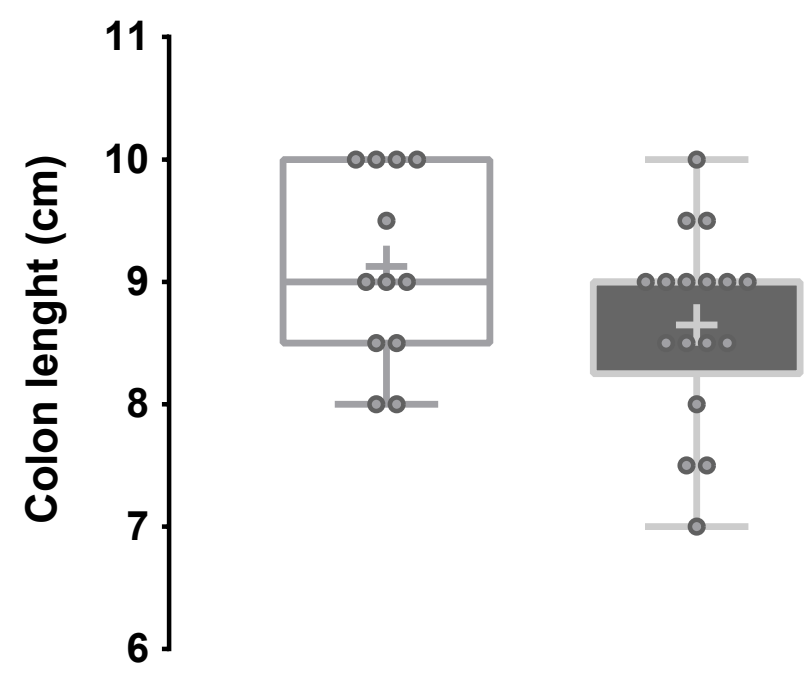

Control

D

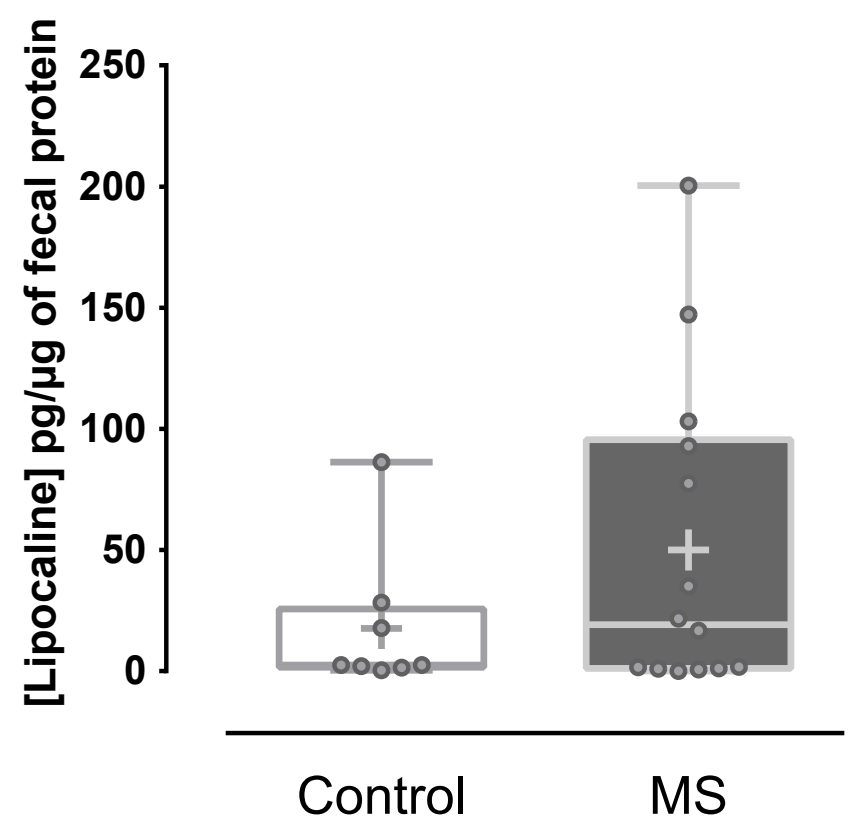




\section{Figure 7}

A
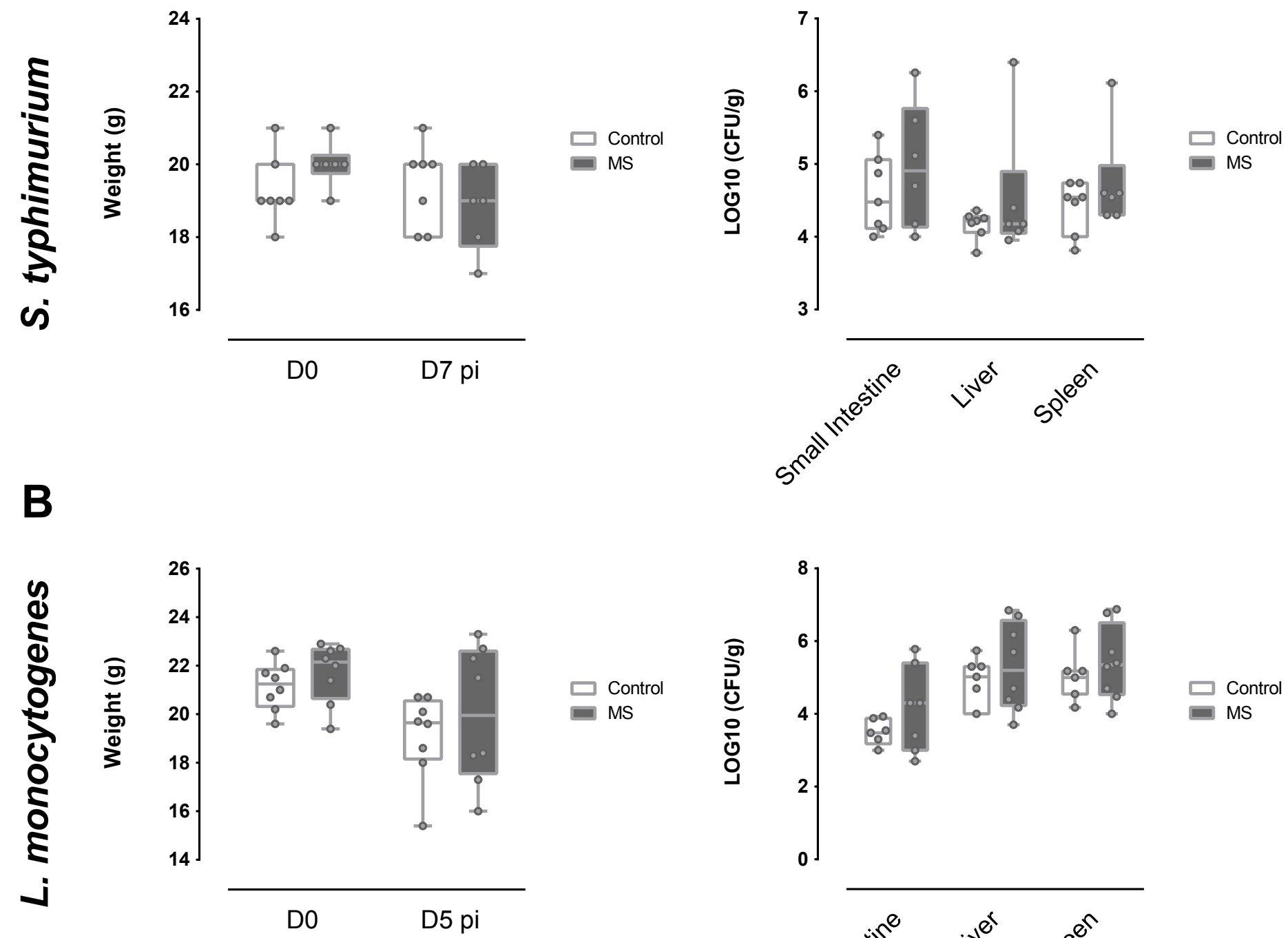

C
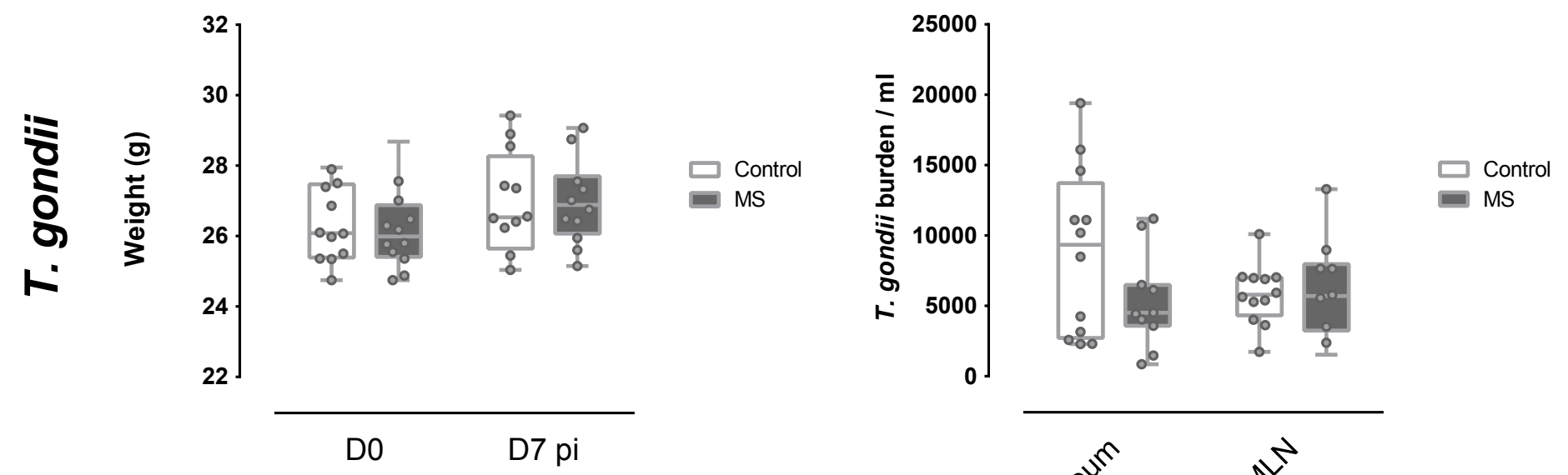


\begin{tabular}{|c|c|c|c|}
\hline Phylum & Class/Family/ Genus & Species /Group & Primers sequences $\left(5^{\prime}-3^{\prime}\right)$ \\
\hline All phyla & All & All & $\begin{array}{l}\text { ACTCCTACGGGAGGCAGCAGT } \\
\text { GTATTACCGCGGCTGCTGGCAC }\end{array}$ \\
\hline Actinobacteria & Bifidobacterium & spp. & $\begin{array}{l}\text { CGCGTCYGGTGTGAAAG } \\
\text { CCCCACATCCAGCATCCA }\end{array}$ \\
\hline Bacteroidetes & All & All & $\begin{array}{l}\text { GGARCATGTGGTTTAATTCGATGAT } \\
\text { AGCTGACGACAACCATGCAG }\end{array}$ \\
\hline Bacteroidetes & Bacteroides /Prevotella & spp. & $\begin{array}{l}\text { GAGAGGAAGGTCCCCCAC } \\
\text { CGCTACTTGGCTGGTTCAG }\end{array}$ \\
\hline Bacteroidetes & Bacteroides & spp. & $\begin{array}{l}\text { CGATGGATAGGGGTTCTGAGAGGA } \\
\text { GCTGGCACGGAGTTAGCCGA }\end{array}$ \\
\hline Bacteroidetes & Bacteroides & fragilis group & $\begin{array}{l}\text { CTGAACCAGCCAAGTAGCG } \\
\text { CCGCAAACTTTCACAACTGACTTA }\end{array}$ \\
\hline Bacteroidetes & Bacteroides & thetaiotaomicron & $\begin{array}{l}\text { GGCAGCATTCAGTITGCTTG } \\
\text { GGTACATACAAAATTCCACACGT }\end{array}$ \\
\hline Bacteroidetes & Prevotella & spp. & $\begin{array}{l}\text { CACCAAGGCGACGATCA } \\
\text { GGATAACGCCYGGACCT }\end{array}$ \\
\hline Firmicutes & All & All & $\begin{array}{l}\text { TGAAACTYAAAGGAATTGACG } \\
\text { ACCATGCACCACCTGTC }\end{array}$ \\
\hline Firmicutes & Lactobacillus & spp. & $\begin{array}{l}\text { AGCAGTAGGGAATCTTCCA } \\
\text { CACCGCTACACATGGAG }\end{array}$ \\
\hline Firmicutes & Clostridium & butyricum (Cluster I) & $\begin{array}{l}\text { GTGCCGCCGCTAACGCATTAAGTAT } \\
\text { ACCATGCACCACCTGTCTTCCTGCC }\end{array}$ \\
\hline Firmicutes & Clostridia & Cluster IV (C. leptum group) & $\begin{array}{l}\text { GCACAAGCAGTGGAGT } \\
\text { CTTCCTCCGTTITGTCAA }\end{array}$ \\
\hline Firmicutes & Clostridia & $\begin{array}{l}\text { Cluster XIVa } \\
\text { (C. coccoides-E. rectale group) }\end{array}$ & $\begin{array}{l}\text { ACTCCTACGGGAGGCAGC } \\
\text { GCTTCTTAGTCAGGTACCGTCAT }\end{array}$ \\
\hline Firmicutes & Clostridia/Lachnospiraceae & Ruminococcus gnavus (Blautia) & $\begin{array}{l}\text { GGACTGCATTTGGAACTGTCAG } \\
\text { AACGTCAGTCATCGTCCAGAAAG }\end{array}$ \\
\hline Firmicutes & Eubacterium & hallii & $\begin{array}{l}\text { GCGTAGGTGGCAGTGCAA } \\
\text { GCACCGRAGCCTATACGG }\end{array}$ \\
\hline Firmicutes & Roseburia & spp. & $\begin{array}{l}\text { TACTGCATTGGAAACTGTCG } \\
\text { CGGCACCGAAGAGCAAT }\end{array}$ \\
\hline Firmicutes & Enterococcus & spp. & $\begin{array}{l}\text { CCCTTATTGTTAGTTGCCATCATT } \\
\text { ACTCGTTGTACTTCCCATTGT }\end{array}$ \\
\hline Proteobacteria & Escherichia & coli & $\begin{array}{l}\text { CATGCCGCGTGTATGAAGAA } \\
\text { CGGGTAACGTCAATGAGCAAA }\end{array}$ \\
\hline Proteobacteria & Desulfovibrio & spp. & $\begin{array}{l}\text { CCGTAGATATCTGGAGGAACATCAG } \\
\text { ACATCTAGCATCCATCGTITACAGC }\end{array}$ \\
\hline Verrucomicrobia & Akkermansia & muciniphila & $\begin{array}{l}\text { CAGCACGTGAAGGTGGGGAC } \\
\text { CCTTGCGGTTGGCTTCAGAT }\end{array}$ \\
\hline Euryarchaeota & Methanobrevibacter & smithii & $\begin{array}{l}\text { CCGGGTATCTAATCCGGTTC } \\
\text { CTCCCAGGGTAGAGGTGAAA }\end{array}$ \\
\hline
\end{tabular}




\section{Supplementary Figure 1}

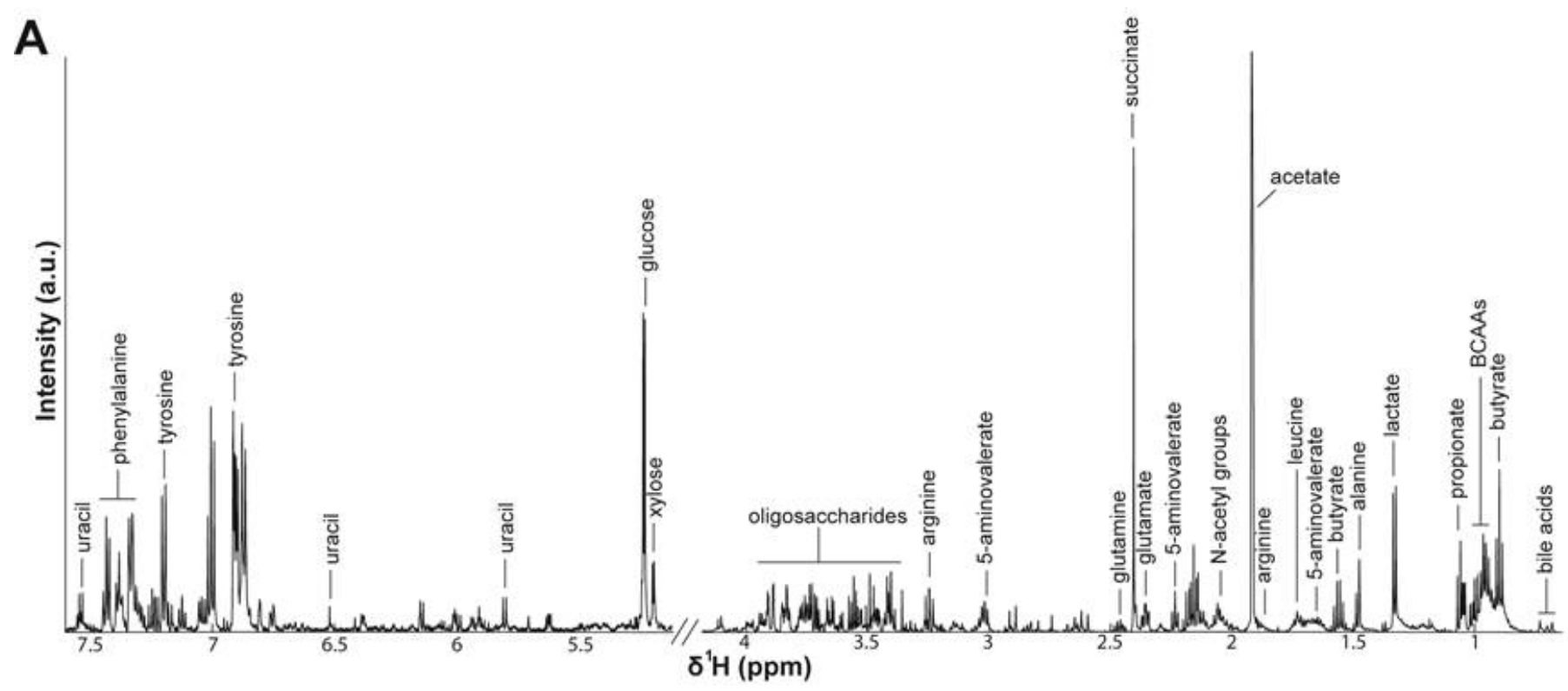

B

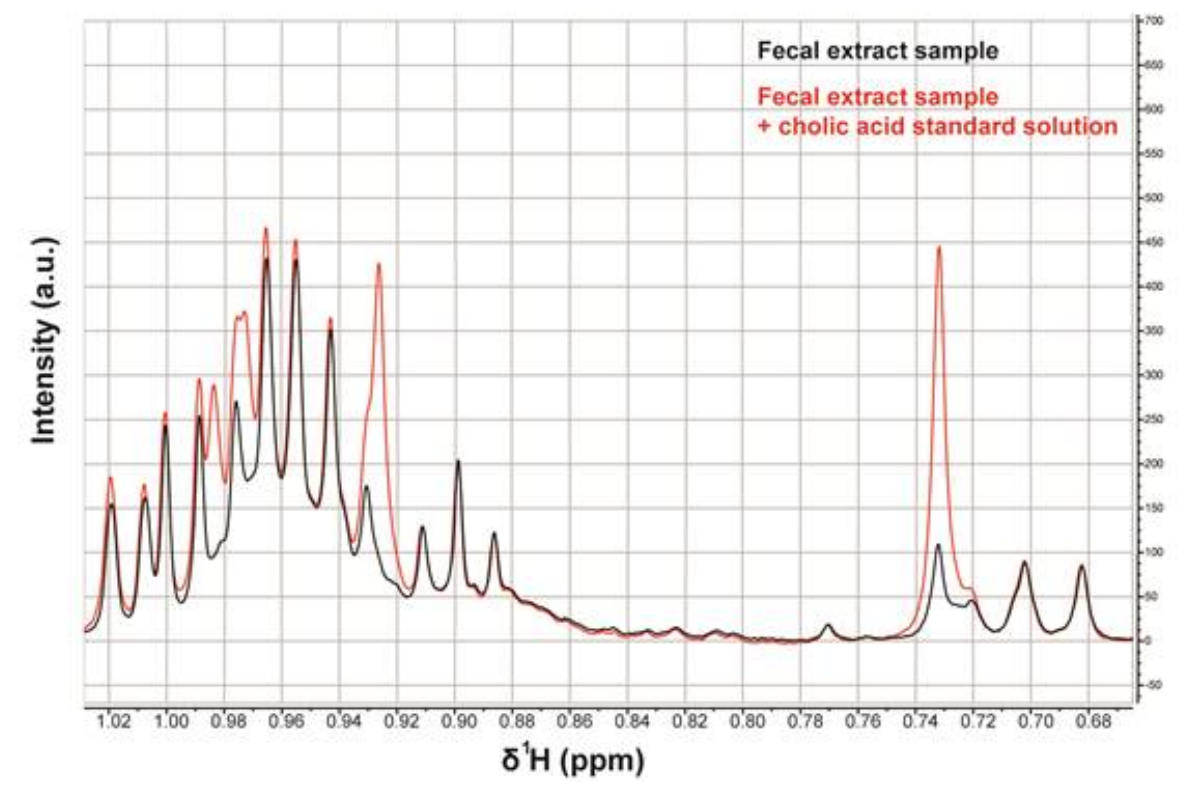




\section{Supplementary Figure 2}
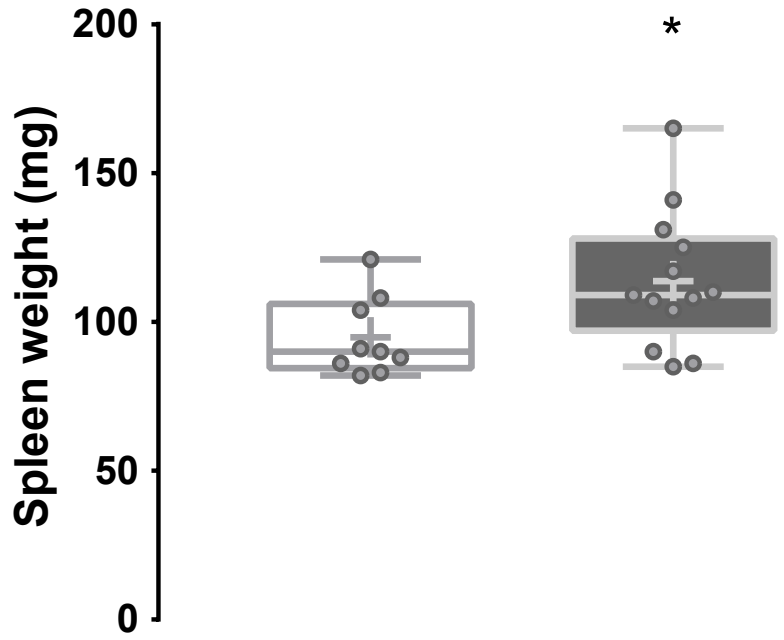

Control MS 